\title{
Empleo rural y LEADER: actores, territorios y beneficiarios en Andalucía (2007-2015)
}

\author{
Rural employment and LEADER: actors, \\ territories and beneficiaries in Andalusia (2007-2015)
}

\section{Eugenio Cejudo García}

cejudo@ugr.es

José Antonio Cañete Pérez

joseaca@ugr.es

\section{Francisco Antonio Navarro Valverde}

favalver@ugr.es

\section{Noelia Ruiz Moya}

noeliaruiz@ugr.es

Departamento de Geografía Humana

Universidad de Granada (España)

\section{Resumen}

LEADER es una de las actuaciones más relevantes en materia de desarrollo rural puesta en marcha por la Unión Europea. Sus repercusiones socioeconómicas, lastradas por su exiguo presupuesto, han sido poco analizadas a escala municipal y para un territorio amplio. Abordamos su cuantificación a través de la inversión y tipo de empleo generado, según promotor, ámbito espacial y perfil de los beneficiados, en los 6225 proyectos ejecutados en Andalucía entre los años 2007-2015. Se constata tanto el desigual comportamiento de los 
diferentes actores según territorios como el menor empleo generado y, dentro de él, creado, respecto del periodo anterior 2000-2006. Son las Sociedades Mercantiles, especialmente las Limitadas, las que más empleo generan. Estas últimas, junto a las personas físicas, son las que más apuestan por la creación de empleo nuevo como forma de autoempleo frente a la crisis, ocupado por jóvenes y mujeres, mayoritariamente. Mientras las primeras benefician sobre todo al colectivo femenino y tienden a concentrarse en las áreas más dinámicas, las segundas adquieren relevancia en el mundo rural. Tanto las asociaciones, por la absoluta presencia de la mujer en ellas, como las Sociedades Cooperativas, por su fuerte implantación territorial y su relación con el sector agrario, juegan un papel relevante.

Palabras clave: trabajo; desarrollo rural; mujer; joven.

\section{Abstract}

LEADER is one of the most relevant actions in rural development launched by the European Union. Its socioeconomic repercussions, weighed down by its meager budget, have been little analyzed from a broad territorial point of view. We approach its quantification through the investment and type of employment generated according to the promoter, territory and profile of the beneficiaries. The 6,225 projects executed in Andalusia between the years 2007-2015 are analyzed, verifying both the unequal behavior of the actors according to territories and the lower employment generated and, within it, created, with respect to the previous period 2000-2006. Commercial Companies, especially Limited Companies, are the ones that generate the most jobs. The latter, along with Individuals, are the ones that most bet on the creation of new employment as a form of self-employment in the face of the crisis, occupied by young people and women. While the former mainly benefit women and tend to be concentrated in the most dynamic areas, the latter acquire relevance in the rural world. Both Associations, due to the absolute presence of women in them, and Cooperatives, due to their strong territorial dimension and their relationship with the agricultural sector, they have a relevant role.

Key words: work; rural development; women; youth.

\section{Introducción y estado de la cuestión}

LEADER (Liaison Entre Actions de Développement de l'Économie Rurale) y el mundo rural europeo se han convertido en inseparables desde que en 1991 surgiera como Iniciativa comunitaria para favorecer su diversificación productiva en pro de su desarrollo. Con aciertos y 
errores, su impacto está fuera de toda duda y su trascendencia va mucho más allá de los resultados cuantitativos de sus actuaciones en una sociedad rural cada vez más compleja. Nos estamos refiriendo, sobre todo, a la progresiva implantación de una nueva filosofía/metodología de intervención sustentada en los postulados del denominado enfoque LEADER. Sus especificidades son: enfoque ascendente y territorial, participación ciudadana en la toma de decisiones, gestión sustentada en partenariados público-privados (Grupos de Acción Local (GAL), carácter integrado e innovador, apuesta por la diversificación productiva y trabajo en red. (European Commission, 2006; High \& Nemes, 2007). No nos cabe duda de que sus 30 años de implementación ha fortalecido el nivel de resiliencia territorial del mundo rural (SánchezZamora et al, 2014) actuando, en algunos casos, como posible freno a los procesos de despoblación (Maroto-Martos \& Pinos-Navarrete; 2019). Con ello se ha favorecido que los espacios rurales sean contemplados, cada vez más, como territorios-recurso, y no solo como territorios-problema, que necesitan la puesta en marcha de estrategias transversales e integradas en cambios territoriales, productivos, sociales y ambientales, a escala nacional (Molina, 2021).

Sin ánimo de ser exhaustivos, son relevantes los progresos acometidos desde el ámbito de la innovación social (Labianca et al., 2016; Lacquement, 2016), entendida como un proceso a través del cual los actores locales movilizan los recursos materiales e inmateriales para responder a las crecientes necesidades de sus territorios (Bosworth et al., 2016; 2020). Implica acciones colaborativas y procesos participativos, que, mediante la satisfacción de las necesidades sociales y logrando aspiraciones y deseos comunes, contribuyen a mejorar la sociedad (Steiner et al., 2021). Moulaert et al. (2017) identifica tres principios clave que caracterizan la innovación social: una forma de entender una amplia gama de actividades orientadas a afrontar los problemas sociales o gestionar las necesidades humanas; implica nuevas prácticas sociales, transformaciones institucionales y/o formas de participación; y sus efectos trascienden las necesidades inmediatas, mejorando las sociedades locales. Así, la innovación social se convierte en un importante activador de capital territorial, a pesar de que los constreñimientos burocráticos han representado a menudo un significante obstáculo para ella (Pollermann et al., 2013).

En sintonía con lo anterior, son evidentes también las aportaciones de LEADER en relación con la creciente participación de diversos actores en los procesos de desarrollo territorial, fundamentalmente en los de diseño e implementación de las estrategias de desarrollo, aunque de forma bastante dispar según colectivos (Lukic \& Obad, 2016), especialmente si de jóvenes y mujeres hablamos (Vercher et al., 2019). A pesar de ello, ha contribuido a crear nuevas identidades y representaciones sociales de las mujeres propiciando su mayor visibilización e 
inclusión social, en un contexto marcado por emergentes realidades socioeconómicas y espaciales en el mundo rural europeo (Nogué, 2016; Salamaña et al., 2016), y, con ello, su progresivo empoderamiento en las esferas personal, familiar, social y política (Cherayi \& Jose 2016).

Otra de las grandes aportaciones de LEADER, no en vano era su objetivo principal, ha sido el impulso de la diversificación productiva del mundo rural europeo, siendo el turismo la palanca en la que sustenta, en muchas ocasiones en demasía, el desarrollo de estos territorios. Desde esta perspectiva la revalorización del patrimonio natural y cultural, tanto para su recuperación y protección como para su puesta en valor, ha jugado un papel determinante. Ya sea a través de sus valores paisajísticos (Mała, 2014; Molinero \& Tort, 2018; Cañizares, 2020; Silva \& Fernández, 2020), ya de sus cultivos como el viñedo (Baraja et al., 2019; Cañizares \& Ruiz, 2020; Fernández \& Vidal, 2020) ya de sus sistemas tradicionales de riego (Canales \& López, 2013; Leibundgut \& Kohn, 2014; Plaza et al, 2019; Mayordomo \& Hermosilla, 2019), entre otros muchos que se podrían citar.

Para este trabajo merece especial atención el fortalecimiento del capital social como pieza clave en los procesos de desarrollo y gobernanza territorial (Nardone et al., 2010; Teilman 2012, Esparcia et al., 2015a). La dinámica promovida por el enfoque LEADER moviliza actores y recursos, gracias a la acción de los GAL, que generan las estructuras para la cooperación entre actores locales (Esparcia, 2014). Como señalan Dargan y Shucksmith (2008), se generan redes y relaciones sociales entre distintos actores locales, entre distintas instituciones y entre instituciones y comunidades, teniendo algunos de los proyectos un profundo impacto en las relaciones entre comunidades, construyendo capital social, incrementando la confianza en los habitantes locales y creando y reforzando identidades colectivas. Además, se fomenta la participación y el desarrollo ascendente generando proyectos menos jerárquicos que los promovidos y controlados por la administración nacional o regional alumbrados desde enfoques descendentes (Papadopoulou et al., 2011).

Menos abordado, en parte por lo cuestionable de los datos, ha sido el tema de su capacidad para generar empleo o, si se quiere, su impacto socioeconómico (Dax et al., 2016). Sí encontramos trabajos relacionados con estudios de caso sobre buenas prácticas relacionadas con el carácter innovador, o no, de sus proyectos (Pollerman et al., 2013) o sobre el bajo riesgo en la elección de los mismos, lo que penaliza a los más creativos y arriesgados, dificultando la puesta en marcha de un nuevo paradigma de desarrollo rural menos sustentado en el turismo. 
Relevante es el trabajo de Rodríguez et al. (2019) que muestra la importancia que en la generación de empleo, especialmente femenino, tienen los pequeños y medianos proyectos financiados por la mayoría de los GAL andaluces frente a las estrategias basadas en grandes inversiones en pocos proyectos (European Commission, 2017).

Como decíamos al inicio de este apartado, también existen sombras en la ejecución de LEADER. Sus efectos no siempre han sido los previstos y en ello concurren motivaciones muy diferentes aunque confluyen en una clara disfunción entre objetivos y medios efectivos para alcanzarlos (Alario \& Morales, 2020). Sus escasos fondos son absolutamente insuficientes para abordar los retos que tiene planteados el mundo rural europeo en el que su despoblación, desigual territorialmente (Molinero \& Alario, 2019), incluso en sus vacíos (Camarero, 2019), es el principal. Referimos algunos de ellos. La menor participación de la sociedad civil en los órganos de decisión de los GAL, consejos y juntas directivas, como señala Thuesen (2010) para el caso de Dinamarca; o de los agricultores en el caso checo (Delin, 2012); o en el diseño de las estrategias de desarrollo y su implementación (Esparcia et al., 2015b; Navarro et al., 2015). El desigual reparto territorial de sus fondos beneficiando a los espacios más dinámicos respecto de los periféricos, interiores y montanos (Cañete et al., 2018; 2020; Cárdenas \& Nieto, 2017). Las repercusiones negativas que generan un exceso de oferta de alojamientos y un bajo nivel del producto creado en relación con el turismo rural (Tirado \& Hernández; 2019). Los mecanismos de clientelismo y poder que surgen de la mano de intereses personales y colectivos de relevantes actores y élites locales, empresarios y políticos mayormente, en los territorios rurales al cobijo de LEADER (Furmankiewicz \& Macken-Walsh, 2016; Pawlowska, 2017), lo que propicia una "lógica local de apropiación" que juega un papel determinante en la elaboración de las estrategias de desarrollo.

Nuestra propuesta de analizar el empleo generado a través de LEADER entre 2007-2015 nos parece relevante y novedosa no solo por la temática abordada, los impactos socioeconómicos de LEADER, sino también por el nivel de detalle de la información con la que se trabaja, los expedientes individualizados de cada uno de los proyectos, para toda la comunidad autónoma andaluza. Nuestro objetivo es analizar estadística y territorialmente el volumen de empleo generado, diferenciando el creado o nuevo del mantenido o consolidado, y el perfil del que lo obtiene, según emprendedor y territorio. Nuestra hipótesis de partida es que los actores con más capacidad de inversión, fundamentalmente privados, serán los que más trabajo generen -inversión y trabajo se asocian de forma positiva-, existiendo una dispar participación de cada uno de ellos según territorios. Los objetivos específicos son: Cuantificar las diferencias 
existentes, según actores y territorios, en relación con el empleo global, el ocupado por mujeres y por jóvenes. Valorar la participación de mujeres y jóvenes en el empleo respecto de su peso demográfico según tipología espacial. Analizar cartográficamente la distribución municipal de las diferentes variables y promotores en Andalucía.

\section{Fuentes, metodología y área de estudio}

La fuente básica utilizada es la relación de los proyectos tramitados (12 855) en el eje LEADER entre 2007 y 2015 proporcionada por la Consejería de Agricultura, Pesca y Desarrollo Rural de la Junta de Andalucía de los que se han seleccionado solo los ejecutados, en total 6225.

Las categorías de promotores son las establecidas en la fuente y las variables analizadas son el número de proyectos, la inversión realizada y el empleo generado, diferenciado el creado del mantenido, y el perfil del beneficiario. La fiabilidad de los datos que ofrece la fuente es máxima en lo que a inversión y ayuda se refiere, siendo menor respecto del empleo. Ello se debe a que la fiscalización que realiza la Unión Europea (UE) se centra en las dos primeras mientras que "descuida" la tercera. También se han observado falta de homogeneidad en los criterios seguidos por los GAL en el cómputo del empleo si bien la mejora existente en el periodo de programación analizado ha sido evidente respecto de los anteriores.

Partiendo del expediente de cada proyecto, los datos se agregan a nivel municipal para su tratamiento estadístico y cartográfico, estudiando solo los municipios que han implementado, al menos, un proyecto con financiación LEADER en el intervalo temporal considerado. Se han descartado los proyectos que no establecen, nítidamente, el municipio en el que se ejecutan. Los datos se presentan en el texto de forma agregada a nivel regional según promotor y tipología territorial establecida.

Para valorar la representatividad territorial de la participación de mujeres y jóvenes en el empleo respecto de su peso demográfico se toma como referencia solo a la población comprendida entre 18 y 64 años, por ser la que más probabilidad tiene de emprender o trabajar, y como colectivo joven el comprendido entre los 18 y 34 años. LEADER entiende por joven al colectivo cuyos miembros tienen menos de 36 años. Además, solo se ha tenido en cuenta la población de los municipios LEADER, en concreto 713 de los 786 actualmente existentes en Andalucía.

Los resultados obtenidos del análisis estadístico se han incorporado a un Sistema de Información Geográfica, ARCGIS 10.6, y las salidas gráficas corresponden a exportaciones en formato jpg de planos vectoriales desde dicha aplicación informática. 
Por otro lado, es conocida la enorme dificultad existente a la hora de establecer una tipología de los espacios rurales españoles por motivos diversos: disponibilidad y fiabilidad de las fuentes presentes e históricas; escala con la que se decide trabajar; variables y umbrales que se utilizan para su concreción, etc. Sin ánimos de ser exhaustivos, conviene recordar que una de las clasificaciones más utilizadas, por la disponibilidad y fiabilidad de la fuente, es la establecida por el Instituto Nacional de Estadística (INE) en base al total de población. La Unión Europea, siguiendo a la Organización para la Cooperación y Desarrollo Económico (OCDE) (2006), ha establecido tres grandes categorías territoriales (predominantemente rurales, intermedias y predominantemente urbanas) a partir de una densidad de referencia de menos de $100 \mathrm{hab} / \mathrm{km}^{2}$ para diferenciar los municipios rurales de los urbanos. Es a escala local donde recientemente han surgido las propuestas más relevantes. Por un lado, Molinero (2019), partiendo de la Ley 45/2007 y tomando como referencia la densidad de población, establece tres categorías dentro del mundo rural: profundo $<5 \mathrm{hab} / \mathrm{km}^{2}$; estancado $5-<25$ y dinámico $25-<100 \mathrm{hab} / \mathrm{km}^{2}$. Su aplicación en Andalucía presenta problemas debido, entre otras, a la significación socioterritorial que tienen las agrociudades. Por otro lado, De Cos y Reques (2019) proponen una tipología según su vulnerabilidad territorial y demográfica usando fuentes cartográficas disponibles en formato SIG y el análisis multicriterio de combinación lineal ponderada. Ello supone un importante avance desde el punto de vista metodológico obteniendo como resultado agregado 9 categorías según su intensidad. Su aplicación en Andalucía también plantea problemas respecto del componente demográfico.

Reig et al. (2016) parten de la clasificación realizada por la UE en base a la densidad de población aunque corrigen las distorsiones ocasionadas por la superficie de los diferentes municipios en su cálculo tomando como referencia espacial de análisis la malla de $1 \mathrm{~km}^{2}$. Siguiendo requisitos de densidad y población proceden, primero, a caracterizar las celdas rurales y, posteriormente, a construir una tipología municipal a partir de ellas. Así, un municipio se clasifica como rural si al menos el $50 \%$ de su población vive en celdas rurales, o urbano si al menos el $50 \%$ de su población vive en centros urbanos, aunque es posible que se den situaciones intermedias (Reig et al., 2016, p. 39-55). Además, incorporan en su análisis dos variables más para diferenciar los espacios urbanos, rurales e intermedios como son los usos del suelo y la accesibilidad. En el primer caso se utiliza el Sistema de Información de Ocupación del Suelo de España (SIOSE) del IGN (2011) que ofrece un total de 40 tipos distintos de coberturas simples del suelo, de los que siete corresponden a coberturas artificiales (Reig et al., 2016, pp. 59-79). En el caso de los rurales, en consonancia con otros trabajos realizados en 
la UE, recurren a la accesibilidad a los centros urbanos y de servicios, entendidos como las ciudades más próximas con una población superior a los 50000 habitantes (Brezzi et al., 2011), como criterio de clasificación para los territorios rurales. Para su cálculo los autores utilizan la red de carreteras procedente de la Base Topográfica Nacional a escala 1:100 000, BTN100 (IGN, 2014) en formato vectorial. La velocidad de los diferentes tramos se define por el tipo de vía a los que se aplican varios factores de impedancia como son su pendiente, su saturación al transitarse por zonas urbanas y la altitud de los núcleos de población procedente de la Base de Datos de Municipios y Entidades Locales del IGN (Reig et al., 2016, pp. 83-97).

Finalmente, destacamos en relación con Andalucía dos trabajos. Por un lado, el de Lasarte, Rodero y Salinas (2016) que aborda la elaboración de un modelo conceptual de la ruralidad mediante la identificación de sus principales dimensiones así como de las principales variables relacionadas con los niveles de ruralidad para toda la región. Por otro lado, y muy interesante, tenemos el trabajo realizado para el espacio rural de la provincia de Málaga por Larrubia, Navarro y Natera (2019). Mediante el análisis de componentes principales se identifican tres factores que explican la diversidad rural: la transformación productiva, el buen status demográfico y el dinamismo local para, a partir de ellos, establecer dos tipologías diferentes y ocho niveles de ruralidad que reflejan bastante bien las diferencias existentes en el mundo rural malagueño, lo que valida el trabajo realizado.

Nosotros, partiendo de esta última propuesta, hemos utilizado la variable distancia-tiempo también en los municipios intermedios para diferenciar los próximos de los lejanos según se sobrepase o no los 30 minutos. Para los rurales se han establecido tres categorías debido a la diversidad y heterogeneidad de las situaciones observadas: próximo, menos de 45 minutos, lejano entre 45 y menos de 60, y profundo 60 y más. Para los urbanos mantenemos la división establecida por los referidos autores distinguiendo entre cerrados y abiertos según los usos del suelo (Figura 1). 


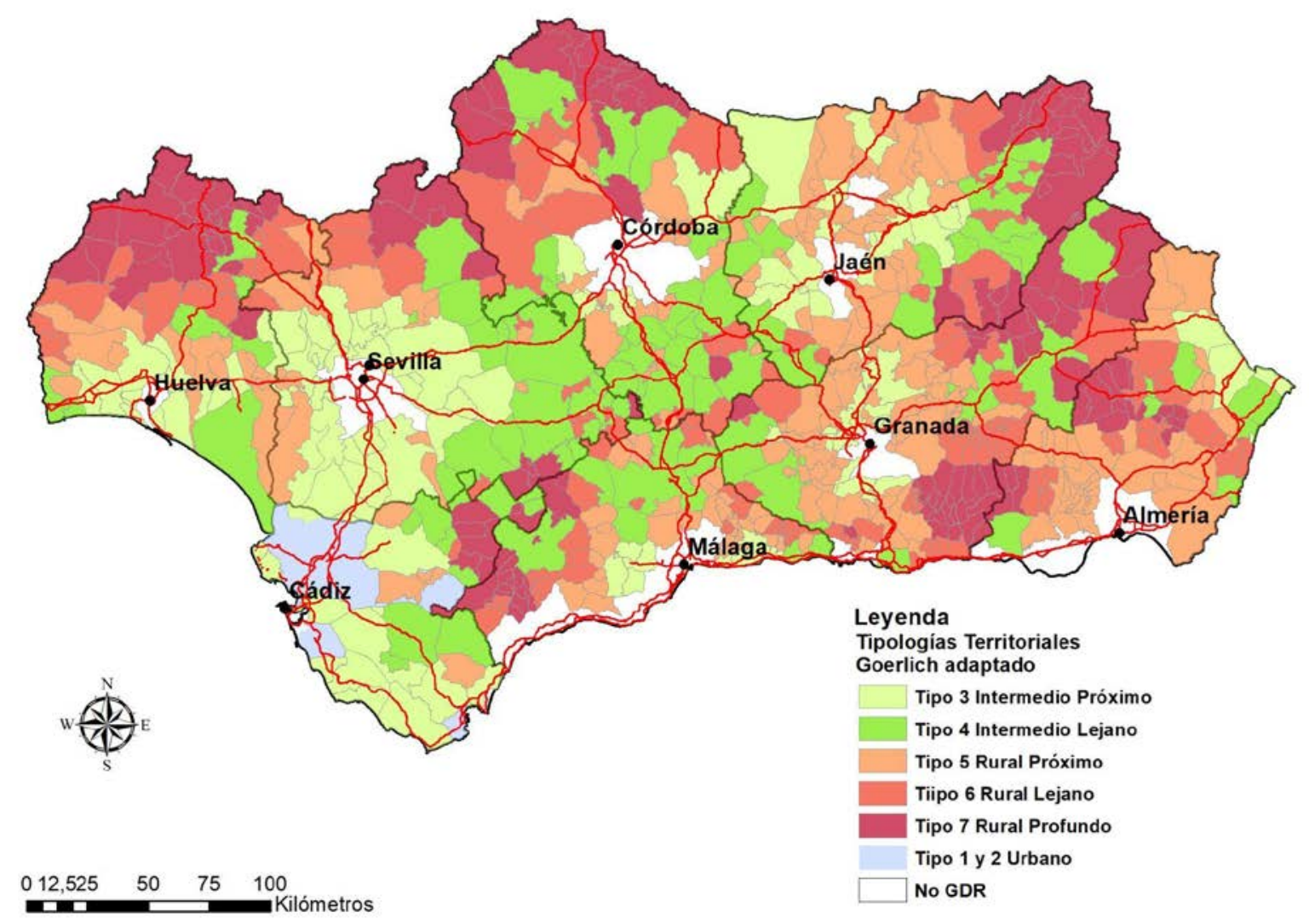

Fuente: elaboración propia siguiendo a Reig et al. (2016)

En la Tabla 1 se presentan algunos indicadores sociodemográficos para caracterizar las tipologías establecidas con datos de 2011, mitad del periodo analizado.

En 2011 los municipios urbanos son en Andalucía el 5,9\% del total, ocupan el 6,7 \% de la superficie, poseen el $50 \%$ de la población y tienen densidades de casi $700 \mathrm{hab} / \mathrm{km}^{2}$, superando los 2500 en los entornos cerrados. Han ganado población durante el periodo analizado, 168940 hab, el 48,3 \% del total regional, manteniendo la tendencia surgida, al menos, desde los años 60 como lo demuestra que entre 1961 y 2011 su población creció más de un 40 \%. Son las zonas más llanas, con altitudes medias inferiores a los 260 metros, y las más próximas a las áreas de prestación de servicios con apenas 4 minutos de tiempo de desplazamiento. Su población es la que presenta una media de edad más baja y un menor peso de la mayor de 64 años, excepción hecha del intermedio próximo. La actividad agraria tiene escasa significación con menos de un 5 \% de afiliados al Sistema Especial Agrario de la Seguridad Social. 
Tabla 1. Indicadores socioeconómicos según tipologías territoriales (2011)

\begin{tabular}{|c|c|c|c|c|c|c|c|c|}
\hline \multirow{3}{*}{ Variables } & \multicolumn{2}{|c|}{ Urbano } & \multicolumn{2}{|c|}{ Intermedio } & \multicolumn{3}{|c|}{ Rural } & \multirow{3}{*}{ Total } \\
\hline & Cerrado & Abierto & Próximo & Lejano & Próximo & Lejano & Profundo & \\
\hline & Tipo 1 & Tipo 2 & Tipo 3 & Tipo 4 & Tipo 5 & Tipo 6 & Tipo 7 & \\
\hline$N^{\circ}$ municipios & 28 & 18 & 125 & 91 & 228 & 132 & 151 & 773 \\
\hline Superficie km² & 826 & 5071 & 16500 & 19170 & 18895 & 12138 & 15186 & 87786 \\
\hline Población & $\begin{array}{c}2086 \\
485\end{array}$ & $\begin{array}{c}2071 \\
715\end{array}$ & $\begin{array}{c}1997 \\
533\end{array}$ & $\begin{array}{c}1225 \\
614\end{array}$ & 555114 & $\begin{array}{l}238 \\
687\end{array}$ & 214696 & $\begin{array}{r}8389 \\
844\end{array}$ \\
\hline Densidad & 2527 & 409 & 121 & 64 & 29 & 20 & 14 & 96 \\
\hline Distancia-tiempo & 3,8 & 3,4 & 17,3 & 45,0 & 30,3 & 51,7 & 73,3 & 40,4 \\
\hline Altitud & 256 & 264 & 267 & 381 & 518 & 631 & 718 & 504 \\
\hline Mujeres (\%) & 51,7 & 51,3 & 49,4 & 50,1 & 49,0 & 49,3 & 49,3 & 50,5 \\
\hline Hombres (\%) & 48,3 & 48,7 & 50,6 & 49,9 & 51,0 & 50,7 & 50,7 & 49,5 \\
\hline Pobl/Municipio & 74517 & 115095 & 15980 & 13468 & 2435 & 1808 & 1.422 & 10854 \\
\hline TCR_2015-2007 & 0,47 & 0,43 & 1,02 & 0,02 & 0,42 & $-0,38$ & $-0,75$ & 0,47 \\
\hline CR-2011-1961 & 43,3 & 41,9 & 36,7 & 1,3 & $-6,6$ & $-7,1$ & $-9,6$ & 100,0 \\
\hline Pobl. 0-14 años & 15,9 & 16,8 & 17,8 & 16,0 & 14,5 & 12,8 & 12,6 & 16,3 \\
\hline Pobl. 15-64 años & 68,9 & 68,9 & 69,6 & 67,5 & 66,7 & 65,4 & 64,2 & 68,5 \\
\hline Pobl. =>65 años & 15,2 & 14,3 & 12,6 & 16,5 & 18,9 & 21,8 & 23,2 & 15,2 \\
\hline $\begin{array}{l}\text { Índice vejez }(65 y+) \\
/(0-14) * 100\end{array}$ & 95,7 & 85,4 & 71,1 & 103,3 & 130,3 & 171,0 & 183,3 & 93,3 \\
\hline Edad media & 37,9 & 37,7 & 38,1 & 40,4 & 43,3 & 45,7 & 46,0 & 42,7 \\
\hline $\begin{array}{l}\text { Afiliados Régimen } \\
\text { General }\end{array}$ & 81,0 & 78,8 & 50,3 & 40,8 & 30,0 & 29,8 & 28,3 & 62,7 \\
\hline $\begin{array}{l}\text { Afiliados Régimen } \\
\text { Agrario }\end{array}$ & 1,2 & 3,6 & 26,5 & 37,4 & 51,1 & 50,3 & 49,2 & 17,7 \\
\hline
\end{tabular}

Fuente: elaboración propia a partir del Instituto de Estadística de Andalucía (2011)

El mundo rural incluye, en la fecha de referencia, al 66,1\% de los municipios, se extiende por el $52,7 \%$ del territorio y cuenta con el $12 \%$ de la población. Reduce sus efectivos entre 2007 y 2015, globalmente, en 1825 personas debido a las pérdidas de las categorías más alejadas, la 6 y la 7, y las ganancias en la más próxima, la 5, que no es capaz de compensarlas. Las diferencias/pérdidas son mayores cuanto más alejado se encuentra el municipio ya que casi la mitad de ellos se producen en la tipología 7. Son municipios situados a mayor altitud, con medias de entre 518 y 718 metros, y con distancias-tiempo que oscilan entre los 30 y los 70 minutos. Su población es la más envejecida, con medias etarias que alcanzan los 46 años, y donde los mayores de 64 años superan el $20 \%$ del total. Y, lo que es más grave, el índice de envejecimiento de su población llega a duplicar la media regional en la categoría 7, 183 frente a 93. Los afiliados agrarios superan el $50 \%$, lo que revela la importancia de la actividad agraria ligada, en gran medida, tanto al olivar como a las prestaciones del Subsidio de Desempleo Agrario y de Renta Agraria que reciben los trabajadores eventuales agrarios de Andalucía y Extremadura (Cejudo et al., 2016a; 2016b).

Finalmente, los municipios intermedios suponen el 27,9\% del total, cuentan con el 40,6\% de la superficie y el $38,4 \%$ de la población. El comportamiento de sus variables presenta, en general, 
una situación que oscila entre las dos tipologías ya comentadas. Ahora bien, llamamos la atención de la 4, intermedio lejano, en la que se incluyen algunas agrociudades, distantes de la prestación de servicios que puede ofrecer lo urbano, 45 minutos de media, pero que se comportan como capitales comarcales que realizan una esencial función de centralidad a la hora de localizar servicios y equipamientos públicos y privados básicos para su entorno rural próximo.

\section{Resultados}

De los 6225 proyectos ejecutados solo analizamos 5747, el 92,3\%, por ser los únicos que identifican el municipio en el que se implementaron. Los 478 proyectos restantes, en más del $90 \%$ de los casos, tienen a las Asociaciones, incluidos los GAL, como promotores. Ahora bien, su incidencia es muy menor en este trabajo concreto ya que los GAL, por normativa, no podían ejecutar proyectos que generaran relevantes niveles de contratación. Para una comprensión más global de los resultados los emprendedores se agruparán en 5 grandes categorías, profundizando después en cada una de ellas: Sociedades Mercantiles (claves A-F); Asociaciones sin ánimo de lucro (claves G-J); Corporaciones Locales (clave P); Personas Físicas (clave PF) y Otras (claves Q-U).

\subsection{Inversión y empleo generado. Balance global}

Antes de abordar el análisis en profundidad del empleo generado por los diferentes promotores según tipologías territoriales y perfil de sus beneficiarios, objeto central de este trabajo, presentamos sintéticamente los valores globales de inversión y empleo en el que enmarcarlo (Tabla 2). 
Tabla 2. Inversión y empleo según promotor y tipología territorial (2007-2015)

\begin{tabular}{|c|c|c|c|c|c|c|c|c|c|c|c|c|c|c|}
\hline \multirow{4}{*}{ Promotor } & \multicolumn{4}{|c|}{ Urbano } & \multicolumn{4}{|c|}{ Intermedio } & \multicolumn{6}{|c|}{ Rural } \\
\hline & \multirow{2}{*}{\multicolumn{2}{|c|}{$\begin{array}{c}\text { Cerrado } \\
\text { Tipo } 1\end{array}$}} & \multirow{2}{*}{\multicolumn{2}{|c|}{$\begin{array}{l}\text { Abierto } \\
\text { Tipo } 2\end{array}$}} & \multirow{2}{*}{\multicolumn{2}{|c|}{$\begin{array}{c}\text { Próximo } \\
\text { Tipo } 3\end{array}$}} & \multirow{2}{*}{\multicolumn{2}{|c|}{$\begin{array}{l}\text { Lejano } \\
\text { Tipo } 4\end{array}$}} & \multirow{2}{*}{\multicolumn{2}{|c|}{$\begin{array}{c}\text { Próximo } \\
\text { Tipo } 5\end{array}$}} & \multirow{2}{*}{\multicolumn{2}{|c|}{$\begin{array}{l}\text { Lejano } \\
\text { Tipo } 6\end{array}$}} & \multirow{2}{*}{\multicolumn{2}{|c|}{$\begin{array}{c}\text { Profundo } \\
\text { Tipo } 7\end{array}$}} \\
\hline & & & & & & & & & & & & & & \\
\hline & Inver & Empl & Inver & Empl & Inver & Empl & Inver & Empl & Inver & Empl & Inver & Empl & Inver & Empl \\
\hline A & & & 431335 & 40 & 7113250 & 1088 & 2720515 & 291 & 4652029 & 282 & & & 3408139 & 25 \\
\hline$B$ & & & 5002705 & 232 & 52413069 & 3361 & 42327395 & 2196 & 39181225 & 1623 & 18690442 & 805 & 24787875 & 551 \\
\hline$E$ & & & 304243 & 22 & 2068997 & 67 & 2861956 & 91 & 1729632 & 26 & 354694 & 21 & 1355447 & 24 \\
\hline $\mathrm{F}$ & & & 1538330 & 76 & 16461715 & 1677 & 14248203 & 1465 & 15555159 & 715 & 4623645 & 950 & 6939033 & 208 \\
\hline $\begin{array}{l}\text { Sociedades } \\
\text { mercantiles }\end{array}$ & 0 & 0 & 7276613 & 370 & 78057031 & 6193 & 62158070 & 4042 & 61118044 & 2645 & 23668781 & 1776 & 36490494 & 809 \\
\hline$G$ & & & 1027889 & 13 & 4788815 & 146 & 9186820 & 273 & 2333343 & 58 & 1874204 & 88 & 985310 & 51 \\
\hline G14 & & & & & 2552206 & 37 & 3543592 & 85 & 2793750 & 15 & 805666 & 27 & 1035058 & 0 \\
\hline$J$ & & & 36070 & 6 & 2371688 & 111 & 571594 & 34 & 1175565 & 38 & 380141 & 57 & 87603 & 6 \\
\hline Asociaciones & 0 & 0 & 1063959 & 19 & 9712709 & 294 & 13302006 & 392 & 6302658 & 111 & 3060011 & 172 & 2107971 & 57 \\
\hline$P$ & 138625 & 0 & 174076 & 0 & 17532935 & 164 & 19426637 & 317 & 23071041 & 103 & 14399596 & 51 & 21358857 & 83 \\
\hline$P F$ & 332651 & 10 & 1920717 & 83 & 25340604 & 911 & 19799428 & 690 & 20223899 & 593 & 11723926 & 283 & 12819577 & 265 \\
\hline$Q$ & & & & & 100947 & 0 & 742540 & 13 & 466808 & 3 & & & 27635 & 2 \\
\hline$R$ & & & 34263 & 2 & 1377374 & 21 & 2798520 & 54 & 1019705 & 1 & 849322 & 0 & 974980 & 20 \\
\hline$S$ & & & & & & & 8431 & 0 & & & & & & \\
\hline$U$ & & & & & 244101 & 12 & & & & & & & 240886 & 4 \\
\hline Otros & 0 & 0 & 34263 & 2 & 1722423 & 33 & 3549491 & 67 & 1486514 & 4 & 849322 & 0 & 1243501 & 26 \\
\hline Total & 471276 & 10 & 10469629 & 474 & 132365701 & 7595 & 118235633 & 5508 & 112202156 & 3456 & 53101636 & 2282 & 74020400 & 1239 \\
\hline
\end{tabular}

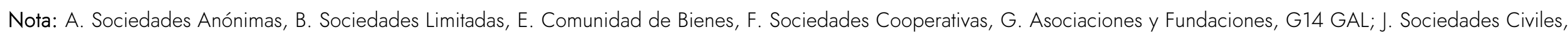

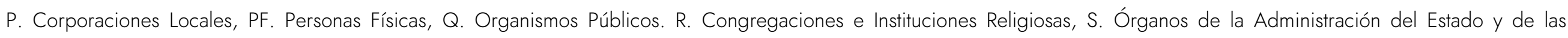
Comunidades Autónomas. U. Otros

Fuente: elaboración propia a partir de la Junta de Andalucía (2018) 
Respecto de la inversión, son las Sociedades Mercantiles sus máximas protagonistas al aglutinar el 53,7\% del total con una media que supera los $155000 €$, llegando a alcanzar los 250000 en las Anónimas. Debe tenerse en cuenta que la inversión media regional apenas supera los $87000 €$. Esta categoría de promotor tiene menos significación en las tipologías más rurales, las lejanas y las profundas. Las Corporaciones Locales, con un 19,2\%, y las Personas Físicas, con el $18,3 \%$, le siguen en importancia aunque con porcentajes sensiblemente inferiores al de los proyectos que ellas ejecutan, lo contrario que ocurre con las Sociedades Mercantiles, lo que se traduce en inversiones medias que no llegan a los $60000 €$. En las segundas no se observa una pauta clara respecto a la distribución territorial de sus inversiones mientras que las primeras son las que más arriesgan en las tres categorías del rural. La relevancia inversora de los GAL es mínima, el $2 \%$, con medias que no llegan a los $41000 €$ y lo hacen en los espacios intermedios, siendo menor su participación en los rurales.

Teniendo en cuenta las limitaciones que los promotores públicos tienen a la hora de invertir en proyectos "productivos", son los actores privados los responsables de la mayor parte del empleo. Las Sociedades Mercantiles generan el $77 \%$ del total, valor muy superior al de la inversión realizada, destacando las Limitadas con el 42,6\% del total. Le siguen las Personas Físicas con el 13,8\%, valor inferior al del dinero desembolsado. Estas dos categorías reúnen más del $90 \%$ del empleo total y del 71,9\% del gasto realizado. Aunque son las Sociedades Limitadas las que más trabajo generan, entendemos muy relevante la aportación realizada por las Cooperativas, básicamente agrarias, con el $25 \%$ del total y el 12\% de la inversión. Por el contrario, las Sociedades Anónimas presentan valores muy inferiores, 3,7 y 8,4\% respectivamente. Era esperable que las Corporaciones Locales solo fuesen capaces de generar el 3,5\% del empleo, con un esfuerzo inversor que quintuplica dicho valor, mientras que los GAL no llegan al 1\%. El montante dinerario medio por puesto de trabajo visibiliza y sintetiza estas diferencias: en las Corporaciones Locales fue de $133846 €$, 5,5 veces más que la media de Andalucía que fue de $24358 €$. La situación contraria se da en las empresas privadas con $16973 €$ de media, lo que supone el 70 \% de la andaluza. En las Asociaciones y las Personas Físicas alcanzaron los 34035 y $32332 €$ respectivamente, valores muy superiores al regional.

Las pautas territoriales del empleo generado siguen, en gran medida, las de la inversión, aunque hay algunas diferencias que merecen ser señaladas.

Primero. Los reducidos porcentajes que presentan las Corporaciones Locales en el mundo rural están por debajo de su media, 3,5\%, en el próximo y lejano pero son superiores en el 
profundo con el 6,7\%. Segundo. En las Asociaciones sus valores se sitúan por debajo de su media, 5,1\%, en cinco de las siete tipologías territoriales, solo se superan en el intermedio próximo y el rural lejano donde alcanza el $7 \%$, dos puntos porcentuales por encima de ella.

Tercero, las Personas Físicas obtuvieron cifras superiores a la media, 13,8 \%, en el rural próximo y profundo. Y lo que es más importante, en este último el 21,4\% obtenido fue superior al de la inversión, 17,3\%.

Cuarto. Las Sociedades Mercantiles, en general, tuvieron un papel más importante en las categorías urbana e intermedia próxima y sus porcentajes más bajos se dieron en las zonas rurales e intermedias lejanas. Ahora bien, y es lo relevante, las Limitadas generaron un gran número de puestos de trabajo por encima de su media, 42,6\%, en el rural próximo, 47\%, y en el profundo, 44,5\%. En las Cooperativas las cifras más llamativas de empleo se dieron en el intermedio lejano y, sobre todo, en el rural profundo con el 41,6\%, su media rondó el $25 \%$.

Finalmente, la distribución municipal de la inversión (Figura 2) y del empleo (Figura 3) permite constatar varios hechos significativos, tanto por separado como relacionando ambas variables. En lo que se refiere a la inversión, el mapa presentado muestra cómo la práctica totalidad de los municipios andaluces incluidos en el ámbito de la iniciativa LEADER han sido receptores de algún proyecto, siendo muy pocos los casos en los que no ocurre así. Otra cuestión distinta es la cuantía de las inversiones realizadas y las tipologías de territorios en los que fundamentalmente se concentran. Tal y como se comprueba en la Figura 2 los municipios con las mayores inversiones se sitúan en los espacios urbanos (como es el caso de Jerez de la Frontera) o en los espacios intermedios próximos y lejanos; es decir en los más dinámicos económicamente (Carmona en Sevilla o Úbeda en Jaén, por ejemplo). Las inversiones de cuantía más baja se registran en los espacios rurales sin que se pueda señalar un comportamiento municipal homogéneo en los tipos próximo, lejano y profundo. Más bien parece que existe una diferencia entre el sector rural oriental y occidental de Andalucía. 
Figura 2. Inversión total por municipios y tipologías territoriales (2007-2015)

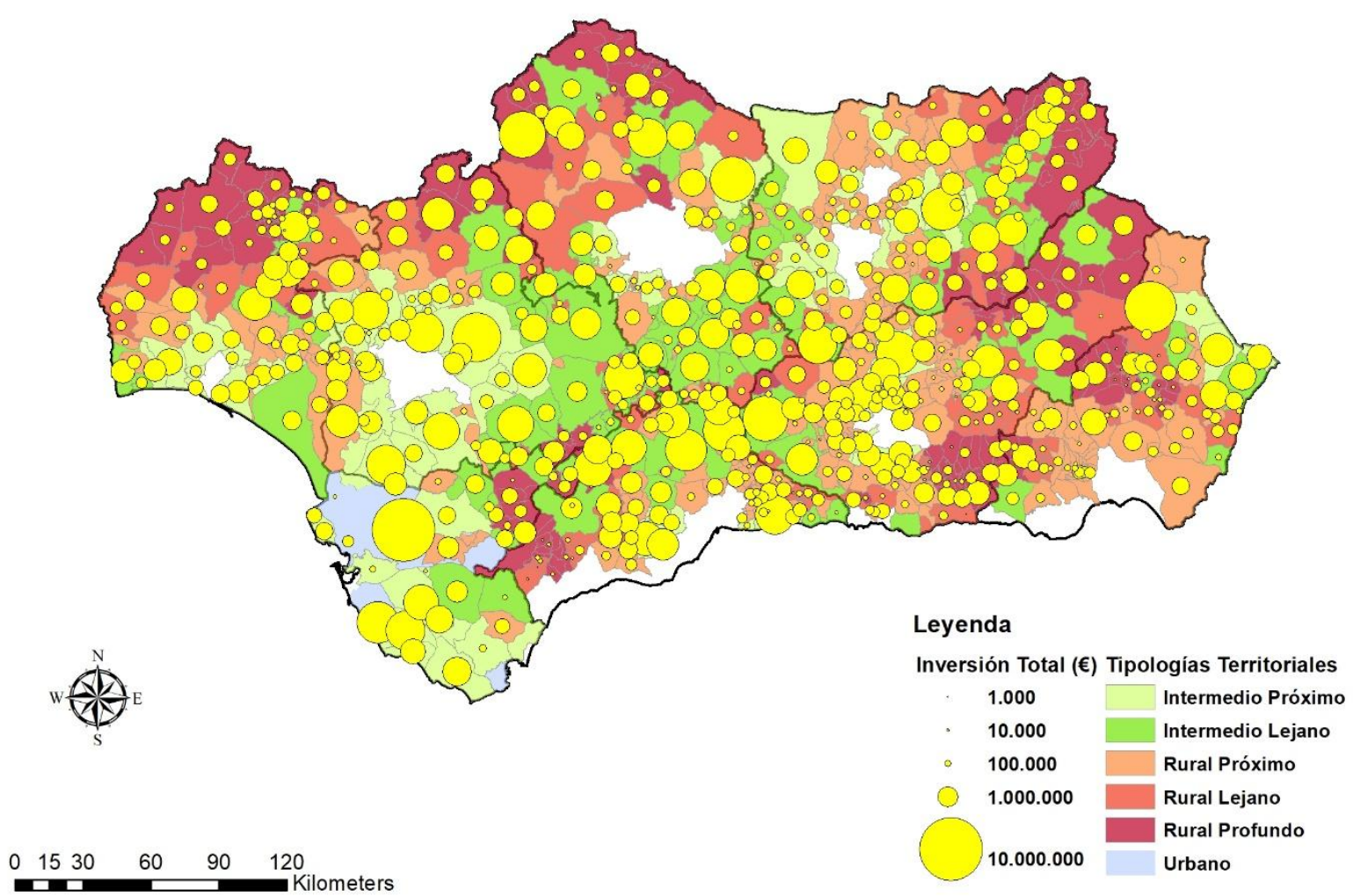

Fuente: elaboración propia a partir de la Junta de Andalucía (2018)

Los efectos de las inversiones sobre el empleo no siguen exactamente estas mismas pautas (Figura 3). Ciertamente, el empleo total (entendiendo como tal al mantenido y creado) se va a concentrar, siguiendo la misma dinámica que las inversiones, en los espacios intermedios próximos y, en menor medida, lejanos. Sin embargo, y esto es una sustancial diferencia, existen 116 municipios, el 17,5\% de los incluidos en zonas LEADER, en los que la inversión realizada no creó ningún empleo. La proximidad a las zonas metropolitanas va a jugar un papel determinante, al igual que ocurría con la inversión. El empleo disminuye drásticamente en los espacios rurales en sus distintas categorías, con valores que frecuentemente son inferiores a 10 empleos/municipio, y en los que, en muchos casos, la inversión solamente ha servido para asegurar el mantenimiento de los existentes. 


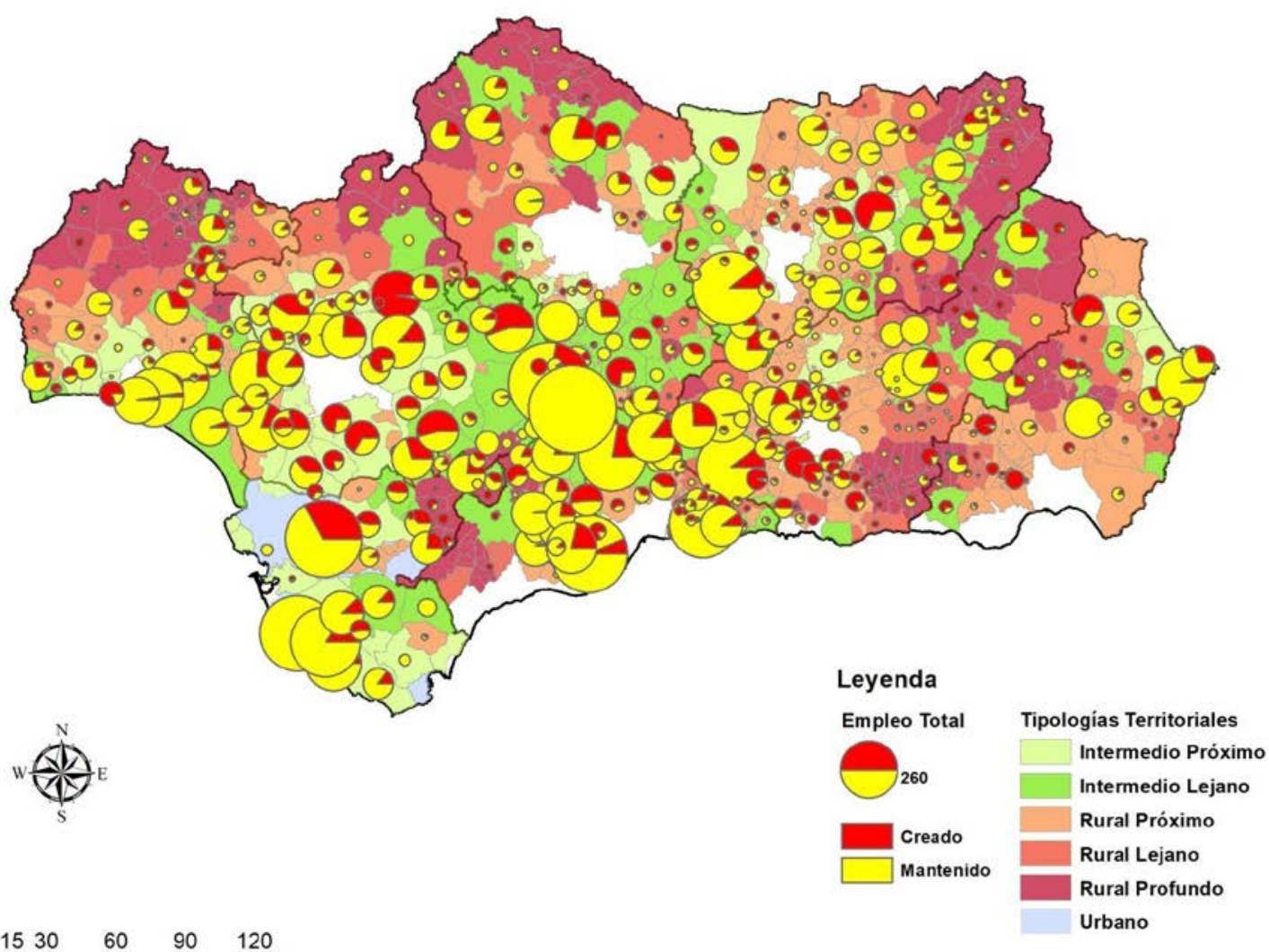

$\begin{array}{lllll}0 & 1530 & 60 & 90 & 120 \\ & & & \end{array}$

Fuente: elaboración propia a partir de Junta de Andalucía (2018)

Espacialmente destacan los entornos de la Janda en Cádiz, el área metropolitana de Sevilla y Granada, así como los municipios en la confluencia de las provincias de Granada, Málaga (Antequera, Ronda) y Sevilla. En lo concerniente al empleo creado, la concentración en las zonas más dinámicas económicamente es evidente, registrándose los índices más elevados también en los espacios rurales intermedios, que constituyen el motor económico de la comunidad autónoma.

\subsection{Tipo de empleo y perfil de los que lo obtienen}

a) Empleo creado/nuevo.

Como ya se dijo, el empleo generado o total ligado a las actuaciones LEADER incluye tanto al empleo nuevo o creado como al empleo mantenido o consolidado, suponiendo el segundo el $76,4 \%$ del total, lo que equivale a 15710 puestos de trabajo, siendo los creados 4852, el $23,6 \%$ del total (Tablas 3 y 4), lo que supone el $50 \%$ del registrado en 2000-2006 que fue 
del 47,3\%. Ello evidencia que las inversiones que se realizan en el periodo que estamos analizando tienen, globalmente, como objetivo básico mantener la viabilidad de la empresa y el trabajo preexistente más que contratar otro nuevo.

Tabla 3. Empleo creado sobre el total (2007-2015) (\%)

\begin{tabular}{|c|c|c|c|c|c|c|c|c|}
\hline \multirow{2}{*}{ Promotor* } & \multicolumn{2}{|c|}{ Urbano } & \multicolumn{2}{c|}{ Intermedio } & \multicolumn{3}{c|}{ Rural } & \multirow{2}{*}{ Total } \\
\cline { 2 - 7 } & Cerrado & Abierto & Próximo & Lejano & Próximo & Lejano & Profundo & \multirow{2}{*}{} \\
\cline { 2 - 7 } & Tipo 1 & Tipo 2 & Tipo 3 & Tipo 4 & Tipo 5 & Tipo 6 & Tipo 7 & \\
\hline A & 0.0 & 37,5 & 8,5 & 20,3 & 9,9 & 0.0 & 48,0 & 12,0 \\
\hline B & 0.0 & 40,9 & 23,8 & 25,0 & 34,5 & 20,7 & 30,5 & 26,7 \\
\hline E & 0.0 & 0,0 & 6,0 & 20,4 & 7,7 & 9,5 & 33,3 & 13,8 \\
\hline F & 0.0 & 25,0 & 9,4 & 7,3 & 8,3 & 2,2 & 7,2 & 7,4 \\
\hline Sociedades mercantiles & 0.0 & 34,9 & 17,0 & 18,2 & 24,5 & 10,7 & 25,7 & 18,7 \\
\hline G & 0.0 & 53,8 & 35,6 & 40,3 & 20,7 & 14,8 & 47,5 & 34,7 \\
\hline G14 & 0.0 & 0.0 & 21,6 & 63,5 & 66,7 & 0,0 & 0.0 & 43,9 \\
\hline J & 0.0 & 0,0 & 44,1 & 29,4 & 36,8 & 7,0 & 50,0 & 31,7 \\
\hline Asociaciones & 0.0 & 36,8 & 37,1 & 44,4 & 32,4 & 9,9 & 47,8 & 35,4 \\
\hline$P$ & 0.0 & 0.0 & 47,6 & 16,7 & 37,9 & 74,5 & 24,7 & 31,8 \\
\hline PF & 60,0 & 18,1 & 48,4 & 48,7 & 44,6 & 35,4 & 42,3 & 45,0 \\
\hline Q & 0.0 & 0.0 & 0.0 & 23,1 & 100,0 & 0.0 & 0,0 & 33,3 \\
\hline R & 0.0 & 100,0 & 0,0 & 5,6 & 0,0 & 0.0 & 0,0 & 5,1 \\
\hline S & 0.0 & 0.0 & 0.0 & 0.0 & 0.0 & 0.0 & 0.0 & 0.0 \\
\hline U & 0.0 & 0.0 & 100,0 & 0.0 & 0.0 & 0.0 & 0,0 & 75,0 \\
\hline Otros & 0.0 & 100,0 & 36,4 & 9,0 & 75,0 & 0.0 & 0,0 & 17,4 \\
\hline Total & 60,0 & 32,3 & 22,3 & 23,7 & 28,6 & 15,1 & 29,2 & 23,6 \\
\hline
\end{tabular}

Nota: * Ver Tabla 2

Fuente: elaboración propia a partir de Junta de Andalucía (2018)

Tomando como referencia la media regional, son las Personas Físicas las que presentan una mayor ratio de empleo creado, el 45,0\%; le siguen las Asociaciones con el 35,4\%, las Corporaciones Locales con el 31,8 \% y, finalmente, en las Sociedades Mercantiles los valores se hunden hasta el 18,7\%. Territorialmente, el empleo nuevo, además de en el mundo urbano, alcanza valores medios muy próximos al $30 \%$ en el rural próximo y profundo, 28,6 y 29,2\% respectivamente, lo que supone entre 5 y 5,6 puntos más que la media regional. Este hecho es destacable en la medida en que la creación de empleo se comporta de forma muy positiva en territorios que, en principio, no serían los más propicios para iniciar una actividad y/o contratar nuevos trabajadores. En efecto, por un lado, el porcentaje de municipios rurales que no han creado ningún empleo nuevo respecto del total que no lo han hecho es inferior al que le corresponde respecto los que han ejecutado proyectos, el 64,5 frente al 70,4\%. Por otro lado, el porcentaje en los que el empleo creado es igual o superior al 50 \%, y sobre todo al $100 \%$, en todas las categorías del rural supera al de su significación dentro del conjunto: en el próximo 37,7 frente a 31,4 \%; en el lejano 26,1 frente a 18,9\%; y en el profundo 23,2 frente a 19,9\%. 
Valores que, en buena medida, se explican por el escaso número de empleos que en ellos se generan, sean creados o mantenidos.

Tabla 4. Empleo creado/nuevo (2007-2015) (\%)

\begin{tabular}{|c|c|c|c|c|c|c|c|c|}
\hline \multirow{3}{*}{ Promotor* } & \multicolumn{2}{|c|}{ Urbano } & \multicolumn{2}{|c|}{ Intermedio } & \multicolumn{3}{|c|}{ Rural } & \multirow{3}{*}{ Total } \\
\hline & Cerrado & Abierto & Próximo & Lejano & Próximo & Lejano & Profundo & \\
\hline & Tipo 1 & Tipo 2 & Tipo 3 & Tipo 4 & Tipo 5 & Tipo 6 & Tipo 7 & \\
\hline A & 0,0 & 9,8 & 5,5 & 4,5 & 2,8 & 0,0 & 3,3 & 4,3 \\
\hline$B$ & 0,0 & 62,1 & 47,2 & 42,2 & 56,5 & 48,4 & 46,4 & 48,2 \\
\hline$E$ & 0,0 & 0,0 & 0,2 & 1,4 & 0,2 & 0,6 & 2,2 & 0,7 \\
\hline $\mathrm{F}$ & 0,0 & 12,4 & 9,3 & 8,2 & 6,0 & 6,1 & 4,1 & 7,8 \\
\hline $\begin{array}{l}\text { Sociedades } \\
\text { mercantiles }\end{array}$ & 0,0 & 84,3 & 62,2 & 56,3 & 65,5 & 55,1 & 56,1 & 61,0 \\
\hline$G$ & 0,0 & 4,6 & 3,1 & 8,4 & 1,2 & 3,8 & 6,6 & 4,5 \\
\hline G14 & 0,0 & 0,0 & 0,5 & 4,1 & 1,0 & 0,0 & 0,0 & 1,5 \\
\hline$J$ & 0,0 & 0,0 & 2,9 & 0,8 & 1,4 & 1,2 & 0,8 & 1,6 \\
\hline Asociaciones & 0,0 & 4,6 & 6,4 & 13,4 & 3,6 & 4,9 & 7,5 & 7,6 \\
\hline$P$ & 0,0 & 0,0 & 4,6 & 4,1 & 3,9 & 71,0 & 5,5 & 4,7 \\
\hline$P F$ & 100,0 & 9,8 & 26,0 & 25,8 & 26,7 & 29,0 & 30,9 & 26,2 \\
\hline Q & 0,0 & 0,0 & 0,0 & 0,2 & 0,3 & 0,0 & 0,0 & 0,1 \\
\hline $\mathrm{R}$ & 0,0 & 1,3 & 0,0 & 0,2 & 0,0 & 0,0 & 0,0 & 0,1 \\
\hline$S$ & 0,0 & 0,0 & 0,0 & 0,0 & 0,0 & 0,0 & 0,0 & 0,0 \\
\hline U & 0,0 & 0,0 & 0,7 & 0,0 & 0,0 & 0,0 & 0,0 & 0,2 \\
\hline Otros & 0,0 & 1,3 & 0,7 & 0,5 & 0,3 & 0,0 & 0,0 & 0,5 \\
\hline Total & 100,0 & 100,0 & 100,0 & 100,0 & 100,0 & 100,0 & 100,0 & 100,0 \\
\hline
\end{tabular}

Nota: * Ver Tabla 2

Fuente: elaboración propia a partir de Junta de Andalucía (2018)

¿Qué ocurre cuando se cruzan las variables actor y territorio? En las Sociedades Mercantiles solo 1,9 de cada 10 empleos son nuevos, aunque son las responsables del $61 \%$ del total del trabajo creado, y únicamente en el rural próximo y profundo se alcanza la ratio de 2,5. Dentro de ellas destacamos el papel de las Sociedades Limitadas por ser las que presentan un porcentaje mayor de empleo creado respecto del total dentro de su categoría, 26,7\%. Este valor se supera en el rural profundo y próximo, 30,5 y 34,5\% respectivamente. Ello es importante en la medida en que son ellas las responsables del 46,4 y del 56,5\% del empleo creado en estos territorios. Por el contrario, no se alcanza un solo empleo nuevo por cada 10 en el caso de las Sociedades Cooperativas en ninguna tipología territorial que no sea la urbana.

Estos diferentes comportamientos, lógicamente, se trasladan a su distribución municipal según el perfil jurídico de estas Sociedades. La presencia de las Sociedades Anónimas es mínima (Figura 4) con proyectos que territorialmente se concentran en los espacios intermedios lejanos y 
próximos del sector occidental de Andalucía. Ofrecen una escasa generación de nuevos empleos (básicamente permiten mantener los existentes al ser empresas que mejoran sus instalaciones) y están totalmente ausentes de las zonas más deprimidas.

Figura 4. Empleos creados y mantenidos por las Sociedades Anónimas (2007-2015)

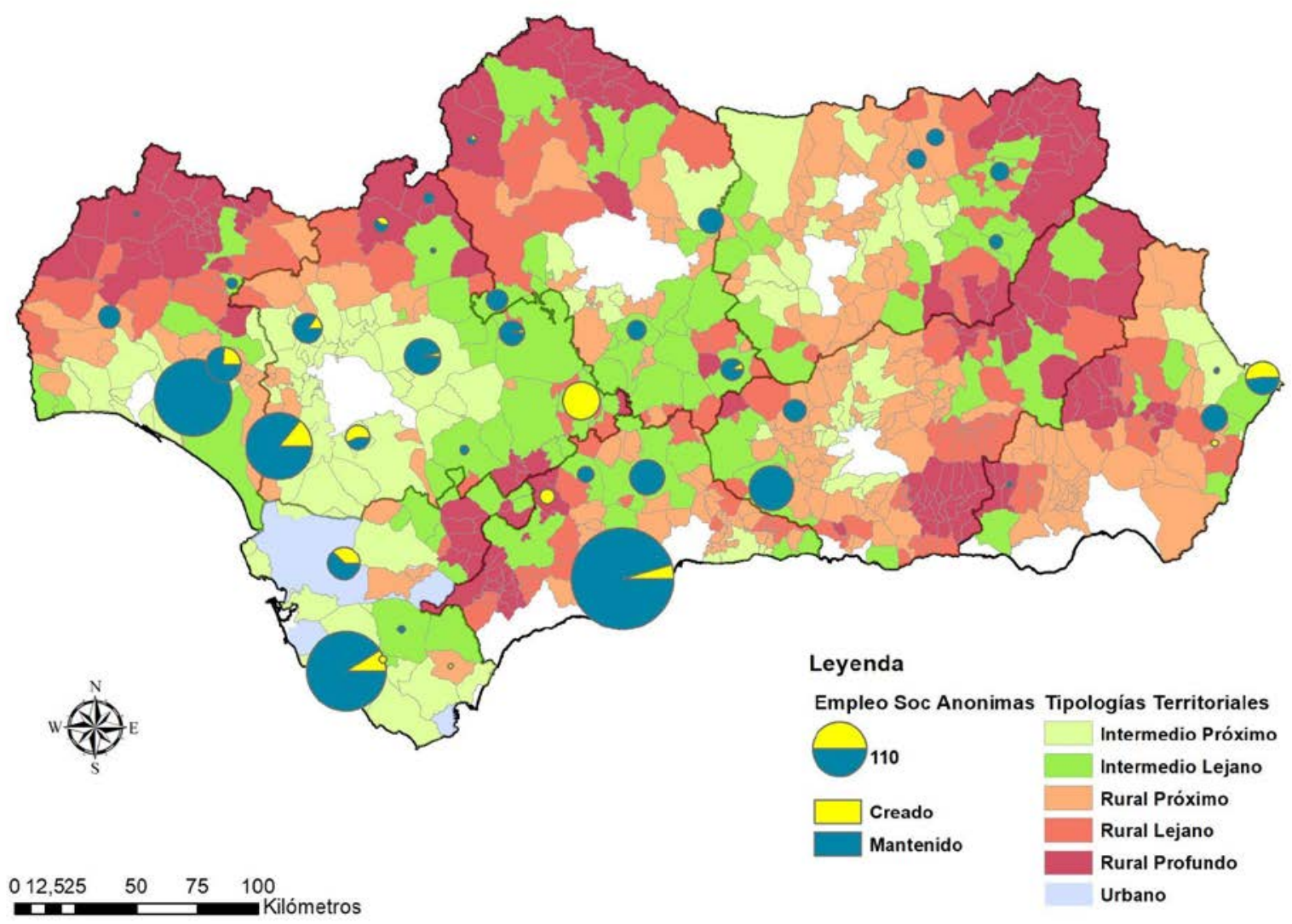

Fuente: elaboración propia a partir de Junta de Andalucía (2018)

No ocurre lo mismo con las Sociedades Limitadas, es el promotor que mayor incidencia tiene en el empleo, tanto consolidado como creado. El contraste de la Figura 5 en relación con la Figura 4 es muy esclarecedor de lo que decimos. Es verdad que la mayor parte de los empleos creados se localizan en los espacios urbanos e intermedios - próximos y lejanos-, siendo aquí donde se alcanzan las mayores ratios municipales-. Ejemplo de este tipo de espacios, agrociudades, pueden ser Écija o Morón de la Frontera en Sevilla. Sin embargo lo más destacable es su presencia en los espacios rurales, ya que ayudan a sostener el reducido tejido productivo existente, manteniendo los empleos de las empresas allí localizadas, y, en otros casos, posibilitando la creación de otros nuevos. Municipios con este comportamiento se encuentran repartidos por prácticamente la totalidad de las zonas serranas andaluzas, como pueden ser Chirivel en Almería, Banalúa en Granada o Cortegana en Huelva. Son formas 
societarias que en muchas ocasiones se ligan a la autopromoción y el autoempleo a través de esta forma jurídica. Razón por la cual es frecuente que en los espacios rurales profundos y lejanos generen un único empleo (el del promotor) y raramente más de 5.

Figura 5. Empleos creados y mantenidos por las Sociedades Limitadas (2007-2015)

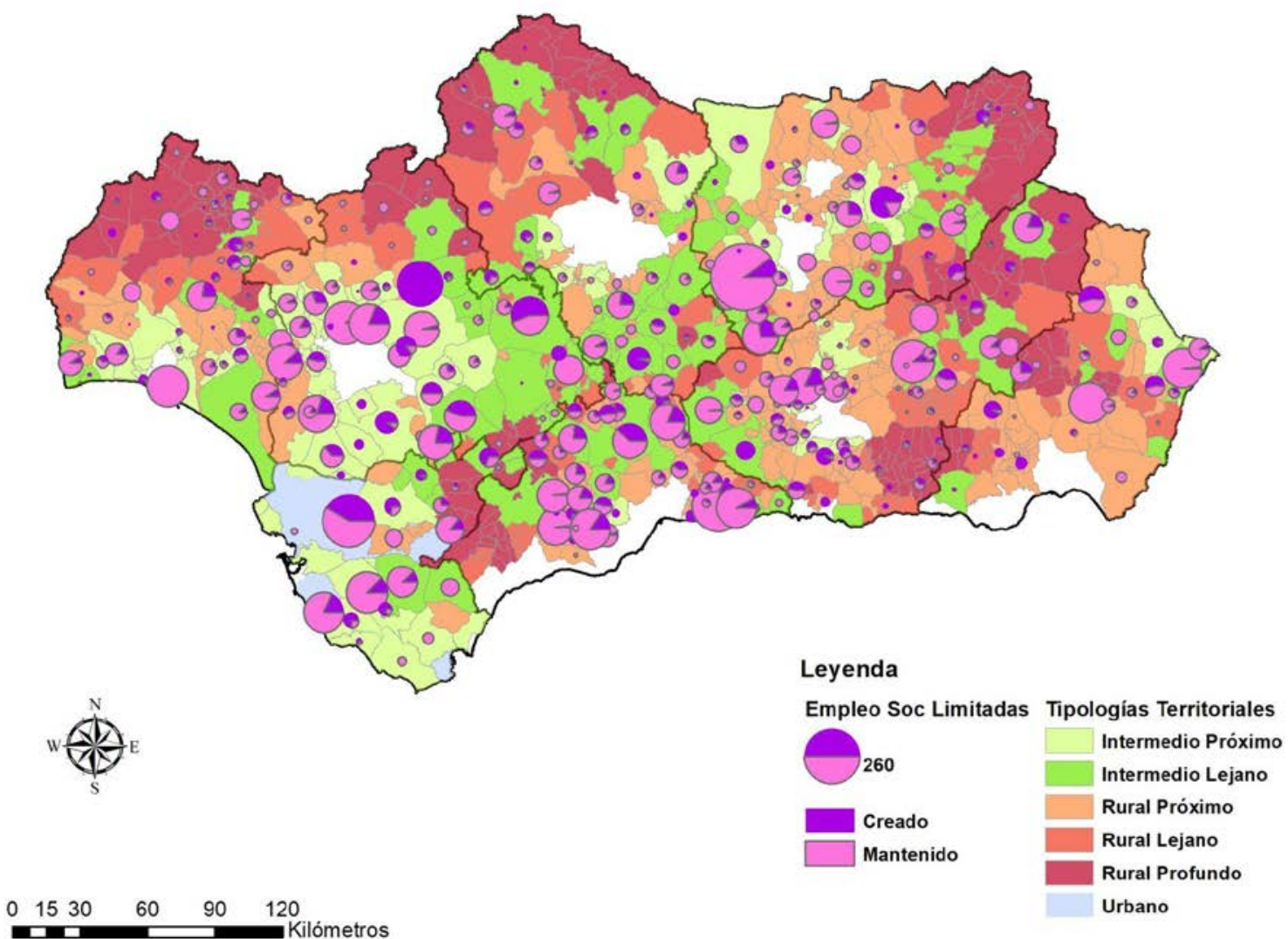

Fuente: elaboración propia a partir de Junta de Andalucía (2018)

El comportamiento territorial de las Cooperativas se puede apreciar en la Figura 6. Lo primero a destacar es su desigual distribución en el territorio pues están ausentes de los espacios rurales profundos e incluso de los lejanos, salvo excepciones. El mapa de referencia muestra su concentración en el eje que tiene su origen en el norte de la provincia de Jaén en la Sierra de Segura, continúa por la comarca de Los Montes orientales (Iznalloz) y occidentales (Montefrio) en la provincia de Granada para adentrarse en la de Málaga en los municipios rurales e intermedios lejanos del valle del Guadalquivir con uno de sus epicentros en Antequera. A grandes rasgos, se podría definir como la "diagonal" olivarera de Andalucía cuya fuerte expansión se ha sustentado en la creación y modernización de cooperativas oleícolas. De ahí que las inversiones realizadas desde LEADER no se hayan orientado tanto a la creación de nuevos empleos como a la consolidación de los existentes a través de la mejora de su 
maquinaria e instalaciones en general. Estructuras cooperativas que se convierten en soporte básico del tejido empresarial de muchos de estos municipios.

Figura 6. Empleos creados y mantenidos por las Cooperativas (2007-2015)

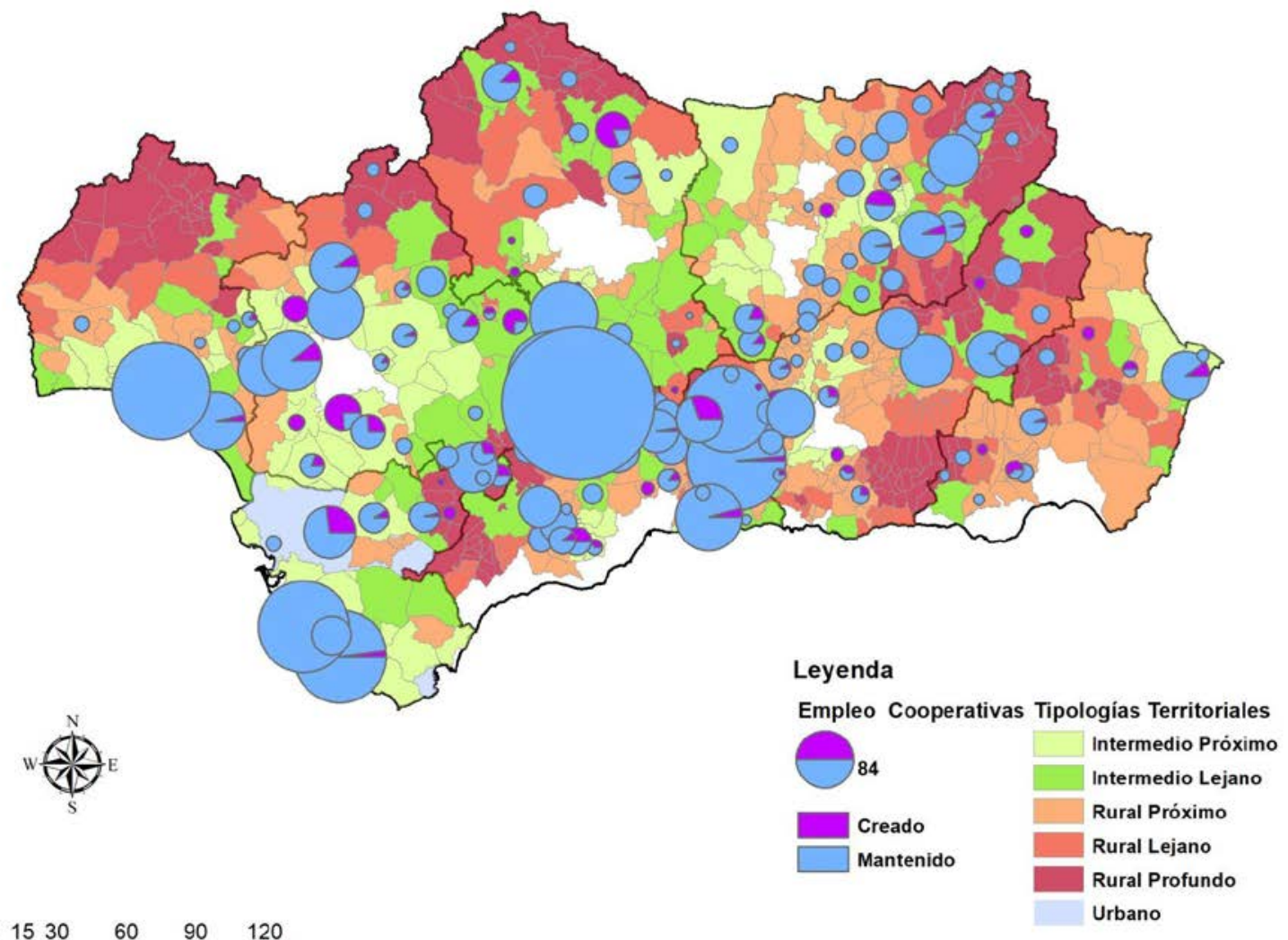

$\begin{array}{lllll}0 & 1530 & 60 & 90 & 120 \\ \text { Kilómetros }\end{array}$

Fuente: elaboración propia a partir de Junta de Andalucía (2018)

En las Corporaciones Locales el 31,8 \% de los empleos generados fueron nuevos. Ese valor se supera en el intermedio y rural próximos con el 47,6 y 37,9\%, respectivamente. Pero es en el rural lejano, aquél que comentamos que ejercía de centralidad respecto de su entorno próximo, donde el 74,5\% es nuevo y, además, supone el $11 \%$ del empleo total. Los valores se hunden en los territorios intermedios lejanos y rurales profundos, probablemente lastrados por los, históricamente, exiguos presupuestos municipales, ahora castigados por la austeridad y los recortes del gasto público, y por su escasa capacidad de generar recursos propios al resultar poco atractivos para la inversión privada.

Las Asociaciones sin ánimo de lucro también crean empleo por encima de la media regional. Los GAL tienen un papel relevante en el intermedio lejano y rural próximo, donde suelen estar localizadas sus sedes, con valores del 63,5 y $66,7 \%$ respectivamente, pero son el resto de 
Asociaciones (categoría G) las que adquieren relevancia en el rural profundo con una ratio del $47,5 \%$, creando el 6,6\% del total de empleo nuevo, y en el intermedio lejano con el 40,3\% de ratio y el $8,4 \%$ del empleo creado total.

Las Personas Físicas, junto a las Sociedades Limitadas como ya dijimos, son las otras protagonistas del empleo creado ya que el 45,0 \% del empleo que ellas generan es nuevo. Ese valor casi alcanza el $50 \%$ en las dos tipologías intermedias, 48,4 y 48,7\% respectivamente, mientras que es inferior en las tres tipologías rurales, sobre todo en la lejana con el 35,4\%. Ahora bien, conviene recordar que es en ellas en las que encontramos los mayores porcentajes de creación de empleo de este promotor, con valores que rondan el 30\% en cada una de ellas. Su distribución municipal se puede observar en la Figura 7. Dos aspectos son relevantes. Primero, tiene mucha significación en los municipios en los que el empleo total es muy elevado, lo que explica que suponga el $45 \%$. Segundo, su extensión territorial incluso en el rural profundo que, aun con pocos proyectos, muestra la apuesta por emprender en ellos. En efecto, es verdad que en el 40,7\% de los municipios con proyectos ejecutados, 262 en concreto, no hay ningún empleo promovido por este colectivo. También lo es que este porcentaje sube entre 6 y 8 puntos en las tipologías rurales al igual que lo es que es éstas donde se localizan el 81,3\% de estos municipios. Ahora bien, en aquellos municipios rurales en los que se genera empleo por parte de este colectivo, el creado cobra un enorme protagonismo. Así, en el 29,6\% de ellos no se crea empleo nuevo mientras que en el 70,4 \% sí se hace. De hecho, el número de municipios en el que el $100 \%$ del empleo es creado es de 96, 123 si incluimos en los que este supone más del 50 \%, que se localizan en municipios rurales lejanos y profundos aunque, fundamentalmente, en los próximos.

En síntesis, si combinamos el volumen de empleo nuevo y lo que este supone respecto del total, dos actores destacan sobre los demás. De un lado, las Sociedades Limitadas en la medida en que combinan alto volumen de empleo creado, alcanzando casi el 50 \% del total en la mayoría de las tipologías territoriales y superándose en el rural próximo, e intensidad respecto del empleo total al sobrepasar ligeramente su media, especialmente, en el rural próximo y profundo. Por otro lado, las Personas Físicas en las que casi la mitad del empleo generado por ellas es nuevo $y$, aunque en el mundo urbano e intermedio el porcentaje es un poco mayor, es en el rural más alejado en el que su volumen presenta mayores niveles respecto del total. Tanto las Asociaciones no GAL como las Corporaciones Locales apuestan también por generar nuevo empleo si bien su intensidad y, sobre todo, su volumen dista mucho de los otros dos actores 
citados; bien es cierto que su mayor relevancia se produce en los espacios rurales, especialmente, profundos.

Figura 7. Empleos creados y mantenidos promovidos por las Personas Físicas (2007-2015)

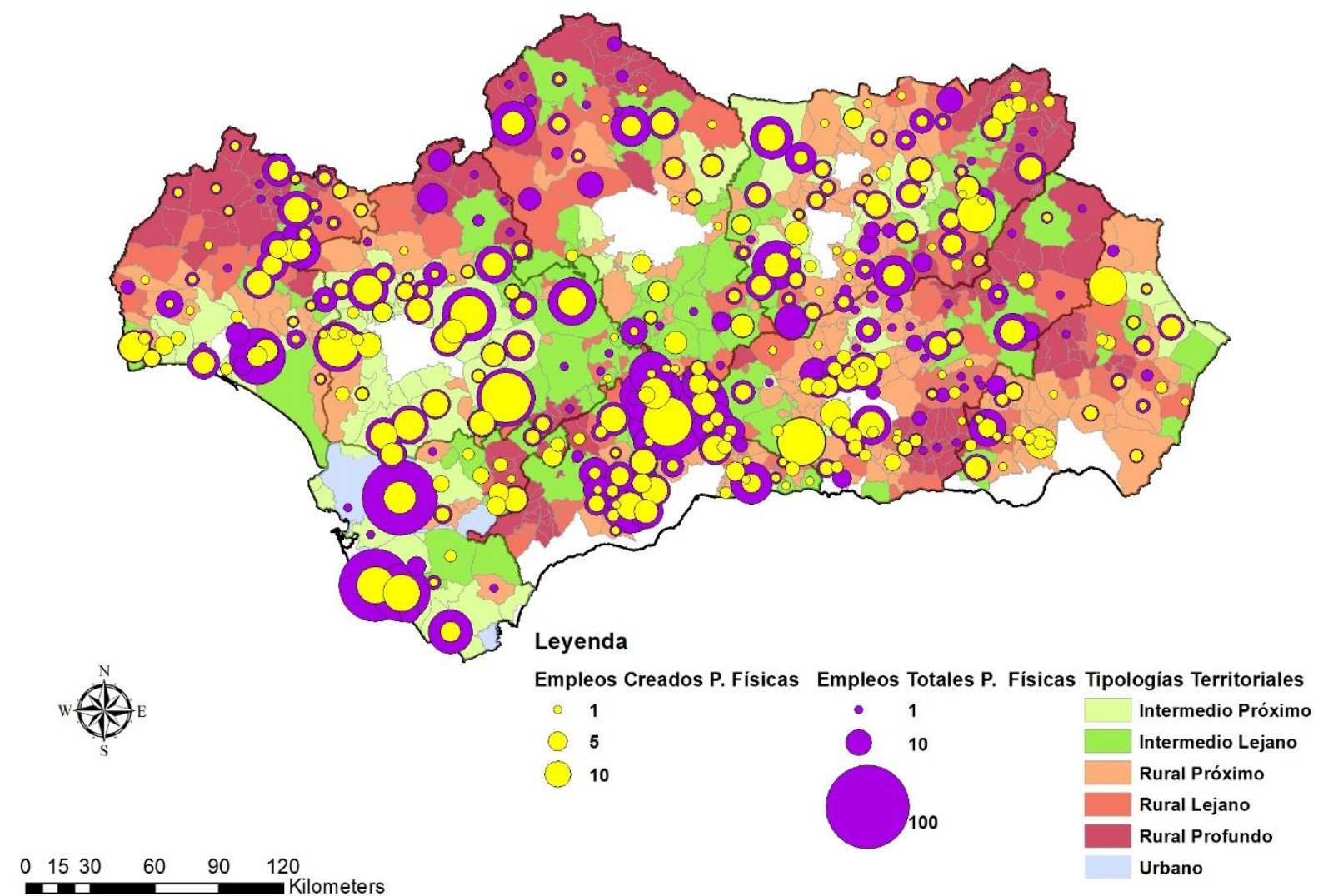

Fuente: elaboración propia a partir de Junta de Andalucía (2018)

b) Empleo ocupado por mujeres

En relación con el empleo femenino los valores recogidos en la Tabla 5 son bastante similares a los del empleo total.

En efecto, el 75,4\% del empleo en el que trabaja la mujer proviene de las Sociedades Mercantiles lo que supone 1,6 puntos menos que el del empleo total. Esta reducción, territorialmente hablando, se produce en los espacios más alejados, tanto del intermedio como del rural, mientras que incrementa su importancia en el próximo, ya sea intermedio, rural o urbano, llegando a alcanzar el 79,6\%. Dentro de ellas las Sociedades Limitadas y las Cooperativas muestran valores muy similares a los del empleo total, en concreto el 41,0\% y el $22,7 \%$, respectivamente, y siguen también la misma lógica territorial. Solo en las Sociedades 
Anónimas encontramos una mayor presencia del empleo femenino respecto del total, 2,5 puntos más, hasta alcanzar el 10,9\% debido, exclusivamente, al incremento de 5,6 puntos registrado en el intermedio próximo que alcanza el 19,9\%.

Tabla 5. Empleo ocupado por mujeres (2007-2015) (\%)

\begin{tabular}{|c|c|c|c|c|c|c|c|c|}
\hline \multirow{3}{*}{ Promotor* } & \multicolumn{2}{|c|}{ Urbano } & \multicolumn{2}{|c|}{ Intermedio } & \multicolumn{3}{|c|}{ Rural } & \multirow{3}{*}{ Total } \\
\hline & Cerrado & Abierto & Próximo & Lejano & Próximo & Lejano & Profundo & \\
\hline & Tipo 1 & Tipo 2 & Tipo 3 & Tipo 4 & Tipo 5 & Tipo 6 & Tipo 7 & \\
\hline A & 0,0 & 3,6 & 19,9 & 4,7 & 6,8 & 0,0 & 1,9 & 10,9 \\
\hline $\mathrm{B}$ & 0,0 & 49,1 & 39,6 & 37,5 & 53,0 & 35,3 & 37,6 & 41,0 \\
\hline$E$ & 0,0 & 6,6 & 0,6 & 1,0 & 0,5 & 1,1 & 1,1 & 0,9 \\
\hline $\mathrm{F}$ & 0,0 & 20,4 & 21,6 & 25,3 & 18,8 & 32,3 & 16,5 & 22,7 \\
\hline Sociedades mercantiles & 0,0 & 79,6 & 81,7 & 68,5 & 79,1 & 68,7 & 57,0 & 75,4 \\
\hline$G$ & 0,0 & 2,4 & 2,8 & 8,9 & 1,6 & 8,6 & 8,0 & 4,9 \\
\hline G14 & 0,0 & 0,0 & 0,7 & 1,7 & 0,5 & 2,8 & 0,0 & 1,1 \\
\hline$J$ & 0,0 & 1,8 & 1,1 & 0,4 & 0,8 & 2,8 & 0,0 & 1,0 \\
\hline Asociaciones & 0,0 & 4,2 & 4,7 & 71,1 & 2,9 & 14,2 & 8,0 & 7,0 \\
\hline$P$ & 0,0 & 0,0 & 2,0 & 4,4 & 1,9 & 3,7 & 10,5 & 3,1 \\
\hline$P F$ & 100,0 & 15,0 & 10,9 & 73,8 & 15,8 & 13,5 & 20,4 & 13,3 \\
\hline$Q$ & 0,0 & 0,0 & 0,0 & 0,2 & 0,2 & 0,0 & 0,2 & 0,1 \\
\hline $\mathrm{R}$ & 0,0 & 1,2 & 0,6 & 2,0 & 0,1 & 0,0 & 3,6 & 1,0 \\
\hline$S$ & 0,0 & 0,0 & 0,0 & 0,0 & 0,0 & 0,0 & 0,0 & 0,0 \\
\hline $\bar{U}$ & 0,0 & 0,0 & 0,1 & 0,0 & 0,0 & 0,0 & 0,2 & 0,1 \\
\hline Otros & 0,0 & 1,2 & 0,7 & 2,2 & 0,3 & 0,0 & 4,1 & 7,1 \\
\hline Total & 100,0 & 100,0 & 100,0 & 100,0 & 100,0 & 100,0 & 100,0 & 100,0 \\
\hline
\end{tabular}

Nota: * Ver Tabla 2

Fuente: elaboración propia a partir de Junta de Andalucía (2018)

Las Corporaciones Locales y las Personas Físicas muestran un comportamiento similar respecto del seguido en el empleo total: reducen levemente sus valores globales aunque, a diferencia de las Sociedades Mercantiles, lo hacen territorialmente en los espacios próximos y los incrementan en los lejanos, sean intermedios o rurales, y profundos.

Las Asociaciones son las únicas cuya significación crece respecto del empleo total. Pasan de generar el 5,1\% al 7,0\% del empleo femenino. Este incremento se produce en todas las categorías territoriales salvo en el caso del rural próximo. Dentro de ellas sobresale la categoría G (Asociaciones y Fundaciones sensu stricto) con un 4,9\%; valor medio que llega al 8 \% en los territorios lejanos y profundos ya sean intermedios o rurales, $8,9,8,6$ y $8,0 \%$, respectivamente.

Ahora bien, ¿̇el empleo que ocupa la mujer se corresponde con el de su peso demográfico en los diferentes territorios? Para dar respuesta a esta pregunta se han construido las Tablas 6 y 7. 
Tabla 6. Caracterización demográfica de la población (2011)

\begin{tabular}{|c|c|c|c|c|c|c|c|c|}
\hline \multirow{2}{*}{ Grupos edad } & \multicolumn{2}{|c|}{ Urbano } & \multicolumn{2}{c|}{ Intermedio } & \multicolumn{3}{c|}{ Rural } & \multirow{2}{*}{ Total } \\
\cline { 2 - 8 } & Cerrado & Abierto & Próximo & Lejano & Próximo & Lejano & Profundo & \\
\cline { 2 - 7 } & Tipo 1 & Tipo 2 & Tipo 3 & Tipo 4 & Tipo 5 & Tipo 6 & Tipo 7 & \\
\hline Mujer_18-64 años (1) & 7119 & 120932 & 485820 & 339484 & 157829 & 69192 & 60817 & 1241192 \\
\hline Pobl. 18-34 años (2) & 5132 & 84752 & 368710 & 253469 & 118723 & 50157 & 43869 & 924813 \\
\hline Pobl. 18-64 años (3) & 14128 & 241065 & 993063 & 696909 & 333631 & 146961 & 129507 & 2555265 \\
\hline$(1) /(3)^{\star} 100$ & 50,4 & 50,2 & 48,9 & 48,7 & 47,3 & 47,1 & 47,0 & 48,6 \\
\hline$(2) /(3)^{\star}$ *100 & 36,3 & 35,2 & 37,1 & 36,4 & 35,6 & 34,1 & 33,9 & 36,2 \\
\hline
\end{tabular}

Fuente: elaboración propia a partir del Censo de Población (2011)

Globalmente, la mujer ocupa el 42,7\% de los empleos lo que supone 5,9 puntos menos que su significación demográfica. Lo mismo ocurre en todas las tipologías territoriales excepto en el intermedio próximo en la que es 3 décimas superior. Otro hecho significativo es que la lejanía a los centros de actividad penaliza a la mujer ya que las diferencias entre su peso demográfico y su participación en el empleo se incrementan negativamente tanto en el intermedio lejano como en el rural lejano y profundo, 9,2, 12,5, y 9,8 puntos, respectivamente. La proximidad reduce las diferencias a 5,6 puntos en el rural próximo e, incluso, la situación se invierte en el intermedio próximo, aunque solo sea por 3 décimas.

Ahora bien, ¿qué ocurre si cruzamos las variables territorio y promotor?

Solo en el caso de las Asociaciones el empleo de la mujer, 59,0\%, supera su cuota de representación demográfica en 1,4 puntos, encontrando en el rural lejano y profundo sus valores más elevados, $65,1 \%$ y $66,4 \%$ respectivamente. Ello se debe a la aportación que hace la categoría $G$ con cifras que superan el $70 \%$ en la mayoría de los territorios, sobre todo en el rural lejano y profundo, 77,3 y 74,3\% respectivamente. Los GAL lo hacen solo en el rural lejano e intermedio próximo.

En las Sociedades Mercantiles solo encontramos en el intermedio próximo un valor que supera, por 4 décimas, su peso demográfico, que se explica por el 68,3\% que registran las Sociedades Anónimas. Por tanto, solo en los territorios más cercanos y con una actividad y dinamismo económico potente encontramos una mayor significación del empleo femenino respecto de su peso poblacional.

Las Corporaciones Locales apuestan claramente por el empleo femenino en los territorios del rural lejano y profundo. Lo demuestra el hecho de que el 56,9 y el $59 \%$, respectivamente, del escaso trabajo que este actor genera lo ocupan mujeres; 11,8 y 12 puntos más que su porcentaje demográfico. 
Tabla 7. Empleo femenino respecto del total (2007-2015) (\%)

\begin{tabular}{|c|c|c|c|c|c|c|c|c|}
\hline \multirow{3}{*}{ Promotor* } & \multicolumn{2}{|c|}{ Urbano } & \multicolumn{2}{|c|}{ Intermedio } & \multicolumn{3}{|c|}{ Rural } & \multirow{3}{*}{ Total } \\
\hline & Cerrado & Abierto & Próximo & Lejano & Próximo & Lejano & Profundo & \\
\hline & Tipo 1 & Tipo 2 & Tipo 3 & Tipo 4 & Tipo 5 & Tipo 6 & Tipo 7 & \\
\hline A & 0.0 & 15,0 & 68,3 & 35,1 & 34,8 & 0.0 & 36,0 & 55,5 \\
\hline B & 0.0 & 35,3 & 44,1 & 37,3 & 47,1 & 34,7 & 31,9 & 41,1 \\
\hline $\mathrm{E}$ & 0.0 & 50,0 & 34,3 & 23,8 & 26,9 & 42,9 & 20,8 & 30,5 \\
\hline $\mathrm{F}$ & 0.0 & 44,7 & 48,1 & 37,7 & 37,8 & 26,8 & 37,0 & 39,2 \\
\hline $\begin{array}{l}\text { Sociedades } \\
\text { mercantiles }\end{array}$ & 0.0 & 35,9 & 49,3 & 37,0 & 43,0 & 30,6 & 33,0 & 41,9 \\
\hline$G$ & 0.0 & 30,8 & 72,9 & 71,1 & 39,7 & 77,3 & 74,3 & 68,9 \\
\hline G14 & 0.0 & 0.0 & 75,7 & 44,7 & 46,7 & 81,5 & 0.0 & 57,9 \\
\hline J & 0.0 & 50,0 & 37,8 & 26,5 & 31,6 & 38,6 & 0,0 & 34,9 \\
\hline Asociaciones & 0.0 & 36,8 & 60,0 & 61,5 & 37,8 & 65,1 & 66,4 & 59,0 \\
\hline$P$ & 0.0 & 0.0 & 44,5 & 30,0 & 27,2 & 56,9 & 59,0 & 38,2 \\
\hline$P F$ & 70,0 & 30,1 & 44,9 & 43,7 & 38,4 & 37,7 & 36,1 & 41,4 \\
\hline$Q$ & 0.0 & 0.0 & 0.0 & 30,8 & 100,0 & 0.0 & 50,0 & 44,4 \\
\hline $\mathrm{R}$ & 0.0 & 100,0 & 100,0 & 81,5 & 100,0 & 0.0 & 85,0 & 86,7 \\
\hline$S$ & 0.0 & 0.0 & 0.0 & 0.0 & 0.0 & 0.0 & 0.0 & 0.0 \\
\hline U & 0.0 & 0.0 & 41,7 & 0.0 & 0.0 & 0.0 & 25,0 & 37,5 \\
\hline Otros & 0.0 & 100,0 & 78,8 & 71,6 & 100,0 & 0.0 & 73,1 & 75,0 \\
\hline Total & 70,0 & 35,2 & 49,2 & 39,6 & 41,7 & 34,6 & 37,8 & 42,7 \\
\hline
\end{tabular}

Nota: * Ver Tabla 2

Fuente: elaboración propia a partir de Junta de Andalucía (2018)

Finalmente, cuando el promotor es una Persona Física las diferencias entre empleo femenino y su significación demográfica siempre son negativas en todas las tipologías territoriales creciendo progresivamente cuanto mayor es el nivel de ruralidad de los territorios. Se pasa del 44,9\% en el intermedio próximo al 36,1\% en el rural profundo lo que se traduce en una diferencia de 4 puntos en el primero y de 10,9 en el segundo entre ambas variables. Si tenemos en cuenta que los proyectos que este colectivo emprende tienen como finalidad el mantener o crear su propia trabajo, como lo demuestra el hecho de que tanto el número de proyectos que ejecuta como de empleos por cada uno de ellos apenas supera el 1, se puede vislumbrar las dificultades que el colectivo femenino tiene a la hora de emprender en los espacios más profundos.

Teniendo en cuenta lo comentado en este apartado, centraremos el análisis municipal en tres actores clave. Las Asociaciones no GAL (Figura 8) por el carácter mayoritario y hegemónico que tiene la mujer dentro del empleo por ellas generado. En su distribución espacial predominan los espacios intermedios lejanos en los que destacan cabeceras comarcales como: Pozoblanco o Cabra (Córdoba), Orcera o Santo Tomé (Jaén), Vélez-Rubio o Purchena (Almería), Guadix o Loja (Granada), Castillo de las Guardas o Écija (Sevilla), Moguer y Palos de la Frontera (Huelva). 
Figura 8. Empleos ocupados por mujeres promovidos

por Asociaciones no GAL (2007-2015)

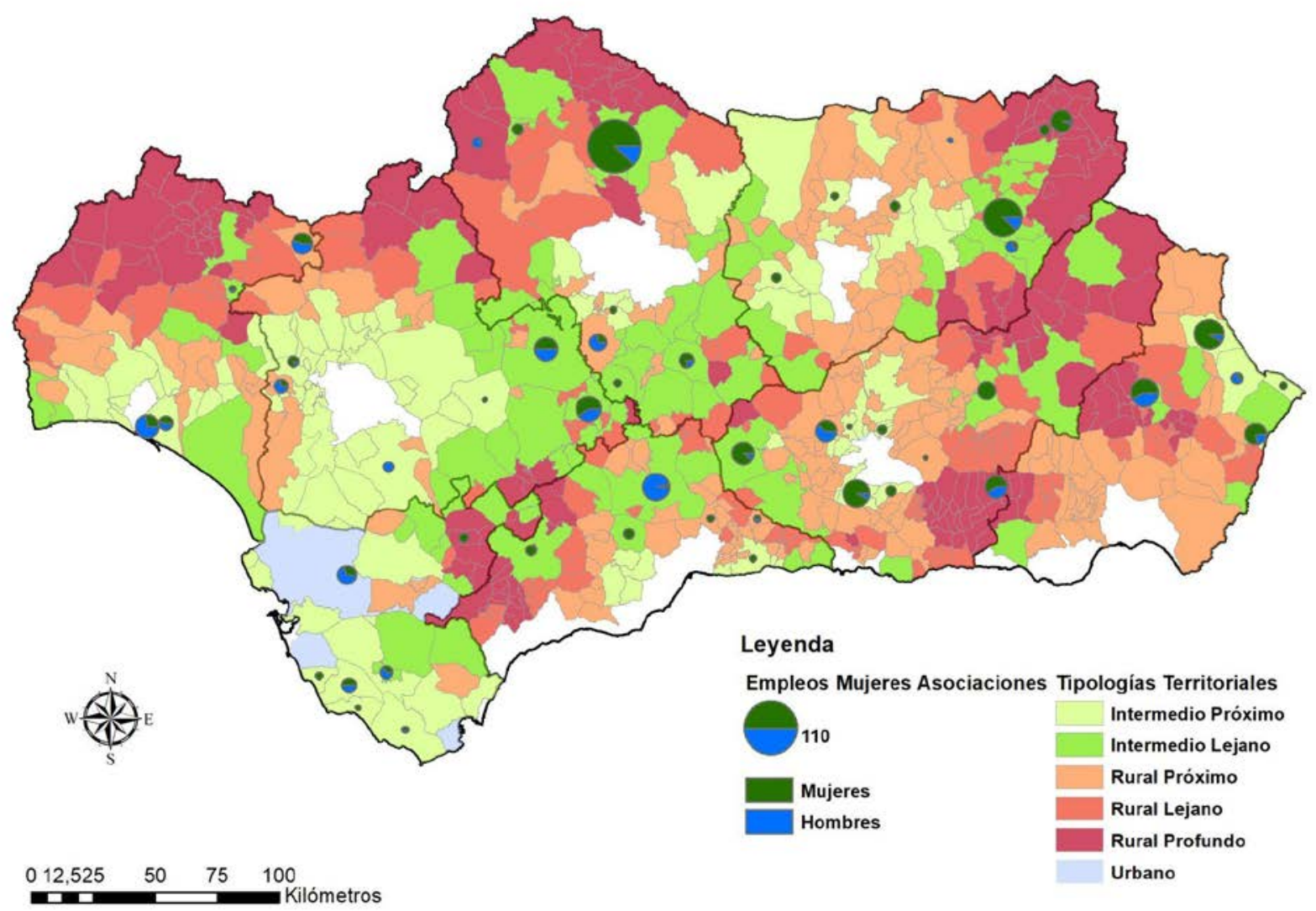

Fuente: elaboración propia a partir de Junta de Andalucía (2018)

Frente a este actor, los dos siguientes, las Sociedades Limitadas (Figura 9) y las Personas Físicas (Figura 10), nos ofrecen una perspectiva distinta y complementaria. Los dos colectivos comparten protagonismo en la generación de empleo femenino como se visualiza en su amplia presencia territorial, bien es cierto que, salvo contadas excepciones, este no suele ser mayoritario. También comparten la tendencia a localizarse en el entorno de las zonas próximas a las áreas metropolitanas de Granada, Sevilla, Huelva o Cádiz. 


\section{Figura 9. Empleos ocupados por mujeres promovidos}

por Sociedades Limitadas (2007-2015)

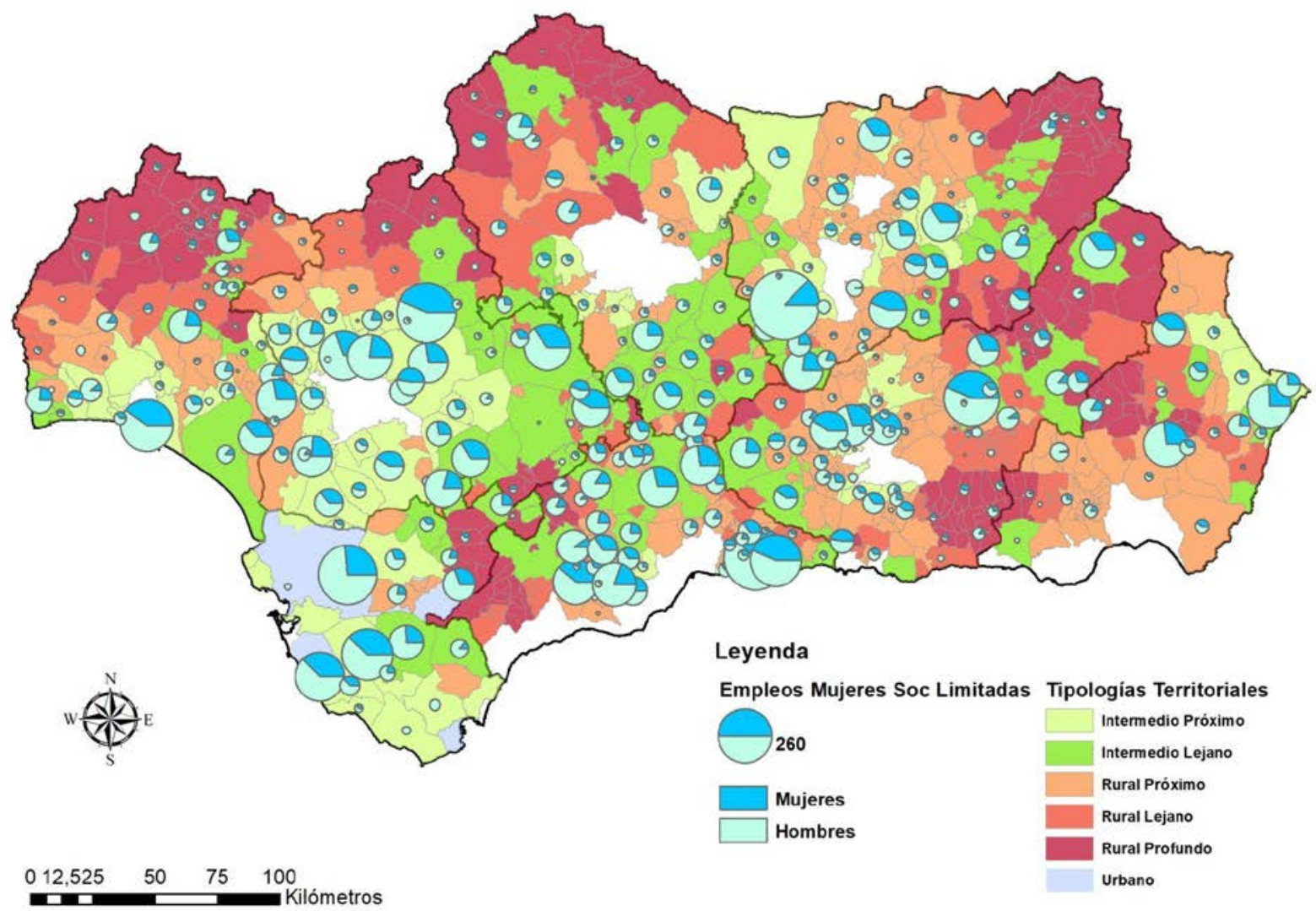

Fuente: elaboración propia a partir de Junta de Andalucía (2018)

Por contra, los separa la mayor presencia de las Sociedades Limitadas en los espacios intermedios e incluso en el rural próximo frente al carácter más rural de las Personas Físicas. Así mientras que las primeras no generan empleo femenino en 285 municipios, el 44,3\%, en las segundas esto ocurre en 262, el 40,7\%. Además, en el caso de las primeras el $87 \%$ de esos municipios sin empleos para las mujeres se localizan en el mundo rural, 6 puntos más de lo que ocurre en el caso de las segundas. Así las cosas, resalta la concentración del empleo femenino generado por las Personas Físicas en la provincia malagueña: el entorno de Antequera, la Sierra de las Nieves o la Axarquía; en los espacios campiñeses y de los Alcores así como de la Sierra Suroeste sevillanas o de la Janda gaditana. 


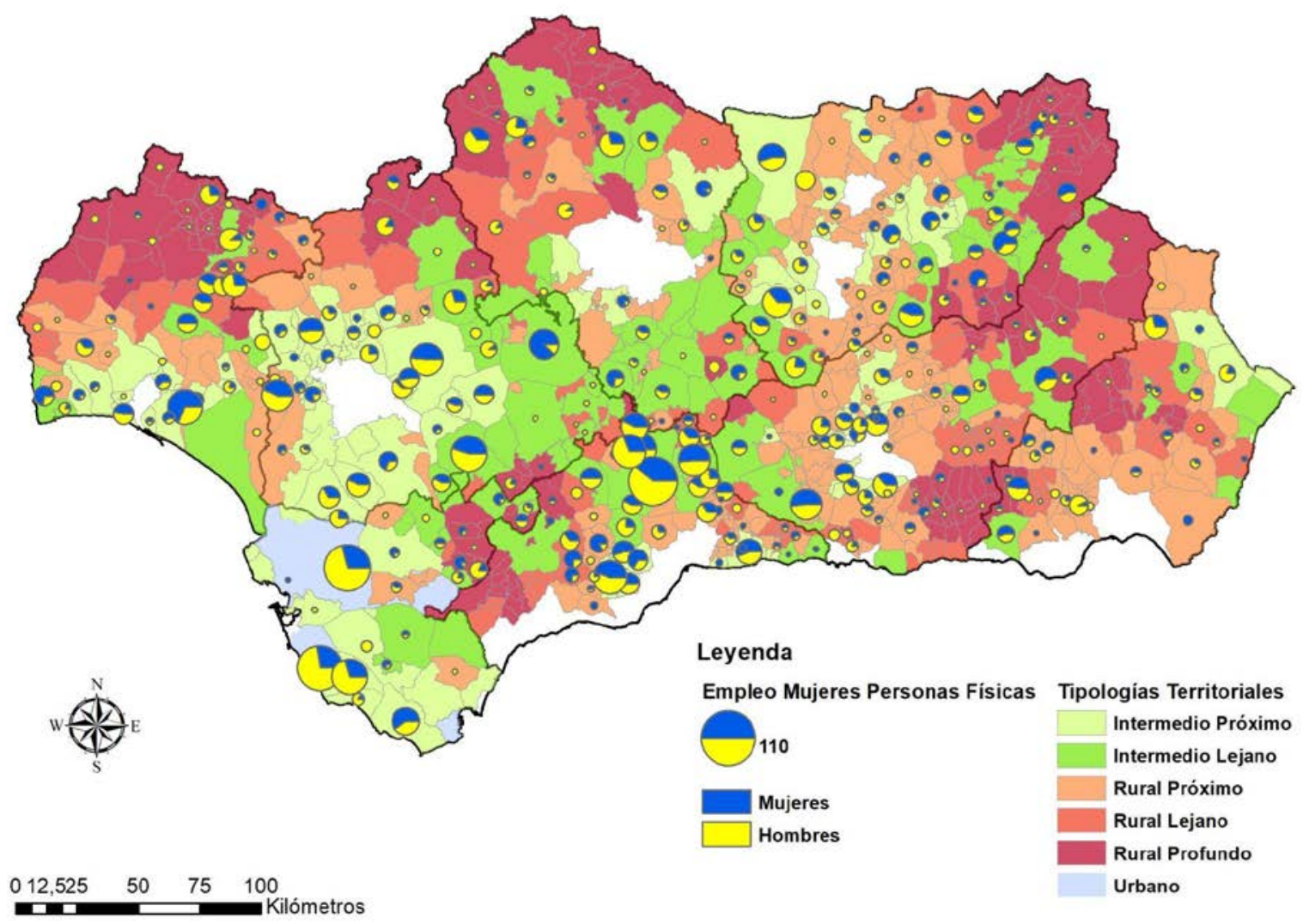

Fuente: elaboración propia a partir de Junta de Andalucía (2018)

\section{c) Empleo ocupado por jóvenes}

Los datos referidos a la población que se toma de referencia para analizar la significación de mujeres y jóvenes en el empleo respecto de su peso demográfico se muestran en la Tabla 6.Junto a la mujer, otro de los actores que requiere de una atención especial en los programas de desarrollo rural como LEADER es el de la juventud.

Nos volvemos a preguntar ¿̇qué importancia relativa tiene el empleo joven respecto del total según promotor y territorio? y ¿cuál es su significación en relación con el peso demográfico de este colectivo en cada uno de ellos? Para dar respuesta hemos construido las Tablas 6, 8 y 9.

El 36,1\% de los empleos totales son ocupados por jóvenes (Tabla 8), valor que es similar al que supone este colectivo respecto de la población comprendida entre 18 y 64 años (Tabla 6). Según tipologías territoriales el empleo joven supera sus porcentajes demográficos en los extremos: en el rural profundo con el 35,9\%, 2 puntos más, y en el intermedio próximo con el $40,1 \%, 2,8$ puntos más. Por contra, es menor, y con diferencias crecientes, en el intermedio 
profundo y rural próximo y lejano, 1,6, 2,2, y 3,8 puntos respectivamente. Si en el análisis incluimos las variables promotor y tipología espacial, observamos que son las Asociaciones, con el $42 \%$, y las Personas Físicas, con el 43,6\%, las que hacen una apuesta clara por el empleo joven con valores que superan su peso poblacional, 5,8 y 7,4 puntos respectivamente. Por el contrario, en las Sociedades Mercantiles sus cifras están un poco por debajo, 1,2 puntos en concreto, de su significado demográfico con el 35,0\%, siendo en las Corporaciones Locales dónde se desploma dicho valor hasta el 22,3 \%, 12,1 puntos menos de lo que este colectivo representa cuantitativamente.

Tabla 8. Empleo joven respecto del empleo total, 2007-2015, (\%)

\begin{tabular}{|c|c|c|c|c|c|c|c|c|}
\hline \multirow{3}{*}{ Promotor* } & \multicolumn{2}{|c|}{ Urbano } & \multicolumn{2}{|c|}{ Intermedio } & \multicolumn{3}{|c|}{ Rural } & \multirow{3}{*}{ Total } \\
\hline & Cerrado & Abierto & Próximo & Lejano & Próximo & Lejano & Profundo & \\
\hline & Tipo 1 & Tipo 2 & Tipo 3 & Tipo 4 & Tipo 5 & Tipo 6 & Tipo 7 & \\
\hline A & 0.0 & 12,5 & 22,0 & 24,1 & 22,0 & 0.0 & 64,0 & 22,7 \\
\hline$B$ & 0.0 & 44,8 & 48,8 & 41,8 & 33,8 & 42,7 & 36,9 & 42,9 \\
\hline$E$ & 0.0 & 81,8 & 10,4 & 35,9 & 23,1 & 23,8 & 50,0 & 32,1 \\
\hline$F$ & 0.0 & 27,6 & 32,7 & 25,3 & 31,0 & 10,3 & 28,0 & 25,9 \\
\hline $\begin{array}{l}\text { Sociedades } \\
\text { mercantiles }\end{array}$ & 0.0 & 40,0 & 39,3 & 34,4 & 31,7 & 25,2 & 35,8 & 35,0 \\
\hline$G$ & 0.0 & 23,1 & 36,0 & 42,1 & 34,5 & 78,4 & 44,6 & 44,9 \\
\hline G14 & 0.0 & 0.0 & 21,6 & 21,2 & 66,7 & 48,1 & 0.0 & 29,9 \\
\hline$J$ & 0.0 & 66,7 & 52,3 & 64,7 & 31,6 & 21,1 & 16,7 & 43,3 \\
\hline Asociaciones & 0.0 & 36,8 & 40,3 & 39,5 & 37,8 & 54,7 & 41,6 & 42,1 \\
\hline$P$ & 0.0 & 0.0 & 38,4 & 8,2 & 31,1 & 41,2 & 21,7 & 22,3 \\
\hline$P F$ & 70,0 & 16,9 & 46,0 & 47,7 & 39,7 & 45,8 & 38,8 & 43,6 \\
\hline$Q$ & 0.0 & 0.0 & 0.0 & 23,1 & 33,3 & 0.0 & 100,0 & 33,3 \\
\hline $\mathrm{R}$ & 0.0 & 50,0 & 28,6 & 25,9 & 0,0 & 0.0 & 45,0 & 30,6 \\
\hline$S$ & 0.0 & 0.0 & 0.0 & 0.0 & 0.0 & 0.0 & 0.0 & 0.0 \\
\hline U & 0.0 & 0.0 & 33,3 & 0.0 & 0.0 & 0.0 & 0,0 & 25,0 \\
\hline Otros & 0.0 & 50,0 & 30,3 & 25,4 & 25,0 & 0.0 & 42,3 & 30,3 \\
\hline Total & 70,0 & 35,9 & 40,1 & 34,8 & 33,3 & 30,3 & 35,9 & 36,1 \\
\hline
\end{tabular}

Nota: * Ver Tabla 2

Fuente: elaboración propia a partir de Junta de Andalucía (2018)

Profundicemos en el comportamiento de los diferentes actores usando las Tablas 8 y 9 . En la categoría de las Sociedades Mercantiles, que son las responsables del 74,7\% de todo el empleo joven regional, las Limitadas presentan un porcentaje medio del $42,9 \%$ con valores máximos del 48,8 \% y 41,8 \% en el intermedio próximo y lejano y del 42,7\% en el rural lejano. En todas las categorías el empleo joven supera al de su representación demográfica. Hecho que es importante en la medida en que son, además, las responsables del 50 \% de todo el empleo de este colectivo; valor que desciende en los entornos rurales e intermedio lejano. Por el 
contrario, la media de las Sociedades Cooperativas, 25,9\%, se desploma hasta el 10,3 y el $25,3 \%$ en el rural e intermedio lejanos, respectivamente. Son las responsables del 17,8 \% de este tipo de empleo, valor que se reduce en los entornos rurales lejanos y profundos y lo supera en los más próximos y dinámicos.

La media de las Corporaciones Locales, 22,3\%, se supera ampliamente en el rural lejano, 41,2 \%, y en el intermedio próximo, 38,4\%. En estos dos casos, sobre todo en el primero, superando los niveles de representación demográfica en 7,1 puntos. Ahora bien, su escasa capacidad de generar este tipo de trabajo, 2,2\%, se supera en las tres tipologías del rural, incluso llega a duplicarse en el profundo, $4 \%$.

Las Asociaciones juegan un papel importantísimo con valores próximos o superiores al 40 \% en todas las tipologías territoriales respecto del empleo total, destacando el rural lejano con el $54,7 \%$ debido al comportamiento de la categoría G (Asociaciones y Fundaciones sensu stricto) en la que el 78,4\% del trabajo que generan es joven. En todos los casos, este sobrepasa la significación demográfica del colectivo. Al igual que ocurría con las Corporaciones Locales, solo generan el 5,9\% del empleo joven total aunque ese valor se supera en el rural e intermedio lejanos. De nuevo el papel de los GAL es irrelevante y solo en el rural lejano son responsables del 1,9\% de este tipo de empleo.

Finalmente, los valores de las Personas Físicas están muy próximos o superan el 40 \% en todas las tipologías territoriales. Sobresalen las del intermedio próximo y lejano y el rural lejano donde casi la mitad de los empleos que generan lo ocupa la juventud: 46,0, 47,7 y 45,8\% respectivamente. Ni que decir tiene que en las dos tipologías no urbanas sus porcentajes superan entre 4,4 y 11,7 puntos su representación demográfica especialmente en los entornos intermedios y en el rural lejano. Además, y nos parece muy relevante, el empleo del que ellos son responsables supera su propia media, recordamos del 16,6\%, en las tres categorías del rural: $20,1,18,7$ y $23,1 \%$, respectivamente.

En síntesis, los empleos ocupados por la juventud representan porcentualmente el mismo valor que el que demográficamente tiene este colectivo, superándose en el intermedio próximo y el rural profundo. Son las Sociedades Limitadas las que realizan un mayor esfuerzo en favor del empleo joven tanto por su volumen total como por la importancia que este tiene respecto del total que ellas generan. A ellas se unen las Personas Físicas, que si bien aportan "solo" un tercio al global andaluz, son en las que el porcentaje de empleo joven respecto del total que generan es superior al de su peso demográfico en el mundo rural en su conjunto y en el profundo en 
particular, al contrario que en las Sociedades Limitadas. Las Asociaciones no GAL también son protagonistas del esfuerzo realizado por emplear a la juventud, especialmente en los espacios lejanos y profundos, si bien su poco volumen en el contexto regional reduce su importancia en términos cuantitativos. Todo lo contrario ocurre con las Cooperativas: alto volumen de empleo joven a nivel andaluz pero bajos niveles de éste respecto del total que ellas generan.

Tabla 9. Empleo joven (2007-2015) (\%)

\begin{tabular}{|c|c|c|c|c|c|c|c|c|}
\hline \multirow{3}{*}{ Promotor* } & \multicolumn{2}{|c|}{ Urbano } & \multicolumn{2}{|c|}{ Intermedio } & \multicolumn{3}{|c|}{ Rural } & \multirow{3}{*}{ Total } \\
\hline & Cerrado & Abierto & Próximo & Lejano & Próximo & Lejano & Profundo & \\
\hline & Tipo 1 & Tipo 2 & Tipo 3 & Tipo 4 & Tipo 5 & Tipo 6 & Tipo 7 & \\
\hline A & 0,0 & 2,9 & 7,8 & 3,6 & 5,4 & 0,0 & 3,6 & 5,3 \\
\hline$B$ & 0,0 & 61,2 & 53,9 & 47,9 & 47,8 & 49,8 & 45,7 & 50,6 \\
\hline$E$ & 0,0 & 10,6 & 0,2 & 1,7 & 0,5 & 0,7 & 2,7 & 1,1 \\
\hline $\mathrm{F}$ & 0,0 & 12,4 & 18,0 & 19,3 & 19,3 & 14,1 & 13,1 & 17,8 \\
\hline $\begin{array}{l}\text { Sociedades } \\
\text { mercantiles }\end{array}$ & 0,0 & 87,1 & 80,0 & 72,5 & 73,0 & 64,6 & 65,1 & 74,7 \\
\hline$G$ & 0,0 & 1,8 & 1,7 & 6,0 & 1,7 & 10,0 & 5,1 & 3,8 \\
\hline G14 & 0,0 & 0,0 & 0,3 & 0,9 & 0,9 & 1,9 & 0,0 & 0,7 \\
\hline$J$ & 0,0 & 2,4 & 1,9 & 1,1 & 1,0 & 1,7 & 0,2 & 1,5 \\
\hline Asociaciones & 0,0 & 4,1 & 3,9 & 8,1 & 3,7 & 13,6 & 5,3 & 5,9 \\
\hline$P$ & 0,0 & 0,0 & 2,1 & 1,4 & 2,8 & 3,0 & 4,0 & 2,2 \\
\hline$P F$ & 100,0 & 8,2 & 13,7 & 17,1 & 20,5 & 18,7 & 23,1 & 16,6 \\
\hline Q & 0,0 & 0,0 & 0,0 & 0,2 & 0,1 & 0,0 & 0,4 & 0,1 \\
\hline $\mathrm{R}$ & 0,0 & 0,6 & 0,2 & 0,7 & 0,0 & 0,0 & 2,0 & 0,4 \\
\hline$S$ & 0,0 & 0,0 & 0,0 & 0,0 & 0,0 & 0,0 & 0,0 & 0,0 \\
\hline U & 0,0 & 0,0 & 0,1 & 0,0 & 0,0 & 0,0 & 0,0 & 0,1 \\
\hline Otros & 0,0 & 0,6 & 0,3 & 0,9 & 0,1 & 0,0 & 2,5 & 0,5 \\
\hline Total & 100,0 & 100,0 & 100,0 & 100,0 & 100,0 & 100,0 & 100,0 & $\begin{array}{c}100, \\
0\end{array}$ \\
\hline
\end{tabular}

Nota: * Ver Tabla 2

Fuente: elaboración propia a partir de Junta de Andalucía (2018)

En este apartado cartografiamos, de nuevo, a las Sociedades Limitadas (Figura 11) y a las Personas Físicas (Figura 12), si bien compararemos su comportamiento con el registrado en el apartado anterior.

En relación con las Sociedades Limitadas (Figuras 9 y 11) los datos muestran y los mapas visibilizan tanto su enorme similitud como la existencia de algunas diferencias. En relación a las diferencias encontramos en que en los municipios en los que se genera un volumen importante de trabajo, que como dijimos se localiza tanto en los territorios intermedios lejanos como próximos, la presencia de jóvenes es en términos relativos mayor que el de la mujer. Ciertamente, será en estos espacios más dinámicos, en los que hay una mayor actividad económica, donde se van a concentrar la mayor parte de las Sociedades Limitadas y en consecuencia el trabajo. Es aquí donde el empleo femenino alcanzará sus mayores valores, al 
igual que el de los jóvenes. Los entornos metropolitanos son especialmente significativos en el caso de los jóvenes, así como en las denominadas agrociudades como son los casos de Martos en Jaén, Écija en Sevilla o Medina Sidonia en Cádiz. (Figura 11)

\section{Figura 11. Empleos ocupados por jóvenes promovidos}

por Sociedades Limitadas (2007-2015)

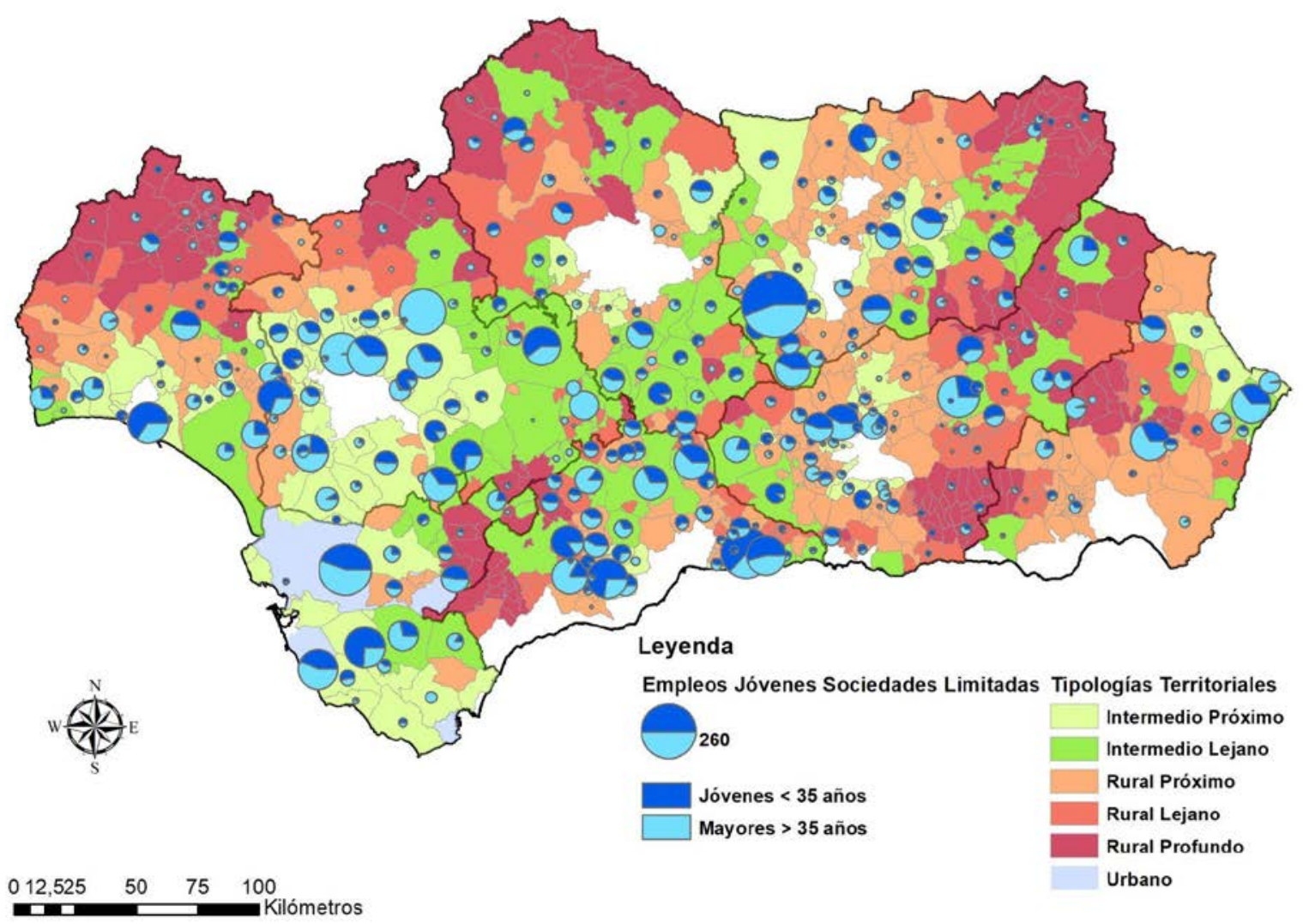

Fuente: elaboración propia a partir de Junta de Andalucía (2018)

El análisis espacial de las Personas Físicas ofrece importantes matices respecto a las Sociedades Limitadas anteriores, ya que estamos ante la figura del autónomo que se autoemplea. Lo primero a destacar es que con los matices lógicos se aprecia un comportamiento muy similar de mujeres y jóvenes (Figuras 10 y 12) que se traduce en un peso muy importante de ambos colectivos en el empleo generado por este tipo de emprendedor. Es cierto que no suelen ser mayoritarios pero tienen un peso muy importante en todas las tipologías territoriales. Respecto de las diferencias en Málaga encontramos espacios en los que el empleo joven es más intenso que el de la mujer, caso de la zona de Antequera, mientras que se reduce considerablemente en la Axarquía y la Sierra de las Nieves; lo mismo ocurre en la Janda gaditana no así en Jerez. Mayor significación de los jóvenes también encontramos en los territorios intermedios en su conjunto, más aún en los 
próximos, como se observa en el caso de Granada o Sevilla, y no así en el caso de Huelva. Por el contrario, en el rural existen situaciones en las que el empleo joven es igual o superior al de la mujer, coincidiendo en mayor medida con el próximo y lejano: Levante almeriense o en Riotinto. En el rural profundo la presencia del empleo joven es menor que el de la mujer en entornos como la Alpujarra granadina y almeriense, el Andévalo onubense aunque no ocurre lo mismo en el Prebético jienense.

Figura 12. Empleos ocupados por jóvenes promovidos por Personas Físicas (2007-2015)

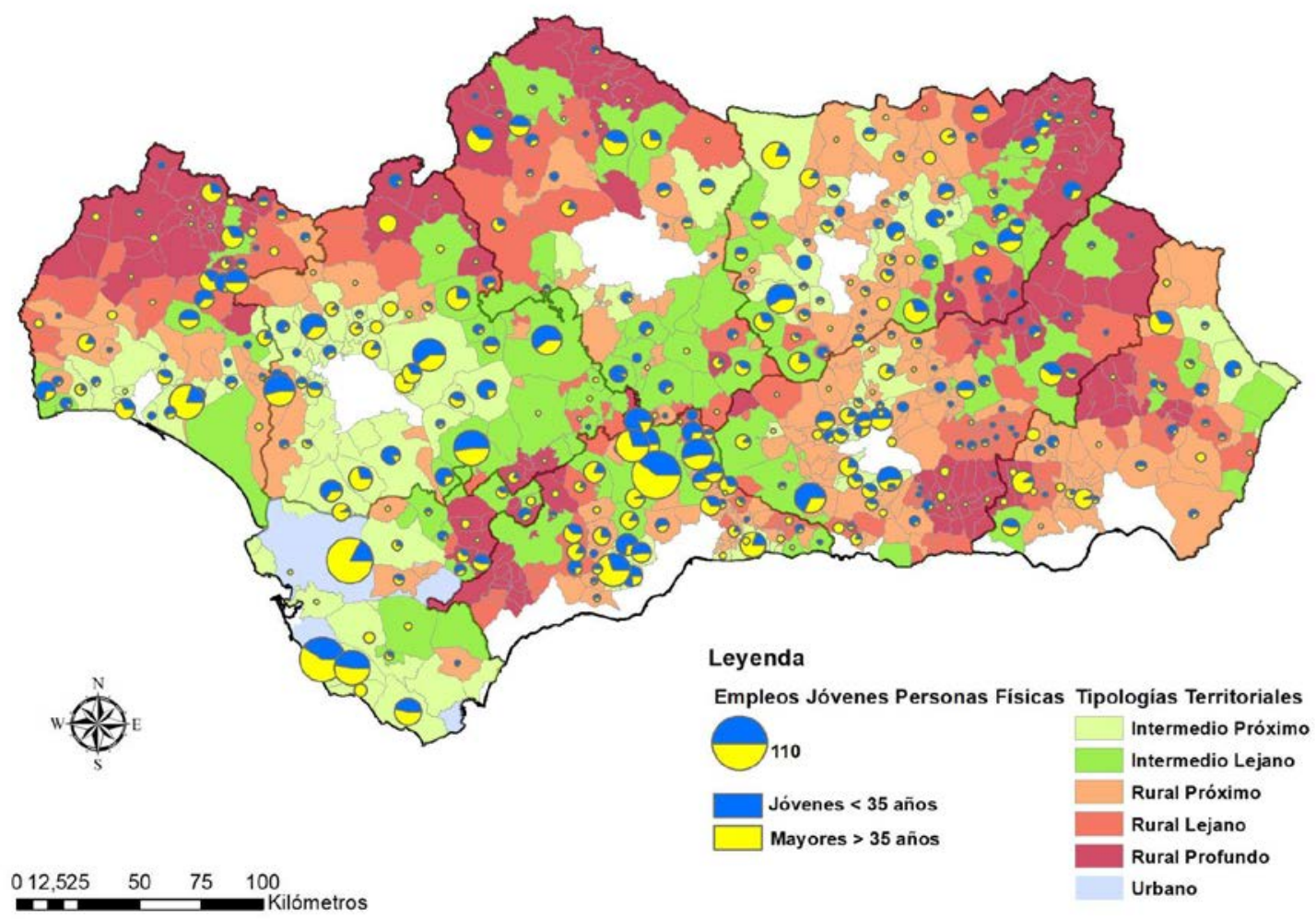

Fuente: elaboración propia a partir de Junta de Andalucía (2018)

En síntesis, el rural, en sus diversas tipologías, ofrece mejores indicadores en el empleo joven que en el de la mujer en la medida en que los municipios rurales en los que, generando empleo, no lo ocupó la mujer fueron el 76 \% mientras que en el caso del empleo joven se reduce al $73 \%$ y, en paralelo, el mundo rural concentra el $77,6 \%$ de municipios con el $100 \%$ de empleo joven frente al $72,1 \%$ en el caso de la mujer. Lo que evidencia una mayor significación del joven varón en este tipo de territorios. En ambos indicadores las diferencias se explican por el comportamiento del rural lejano, en el que encontramos, como ya hemos señalado, un importante número de agrociudades que actúan como cabeceras comarcales. 


\section{Discusión y conclusiones}

La diversidad territorial de Andalucía es un elemento esencial en su articulación territorial aunque dificulta sobremanera su tipificación. A pesar de ello, la división establecida por Reig et al. (2016), adaptada por nosotros en base a las distancias tiempo a los centros de prestación de actividad y servicios, se ha mostrado bastante coherente con la composición espacial de Andalucía. En ella las ciudades medias, de fuerte componente rural-agrario, agrociudades, suponen "una oportunidad para el desarrollo andaluz" (Sánchez, 2018, p. 189). En efecto, una estructura jerárquica y equilibrada de sus asentamientos, su amplia distribución espacial y su enorme diversidad funcional y social terminan conformando espacios favorables para la inversión empresarial con una alta calidad de vida para unos habitantes que priman el llano frente a la montaña, lo grande frente a lo pequeño y la costa frente al interior (Esteve, 2018; Larrubia \& Natera, 2019).

Para la mayoría de los promotores, aunque no de igual forma e intensidad, la lejanía y la ruralidad de los territorios dificultan la implementación de los proyectos LEADER y, como derivada, del empleo que ellos generan; lo contrario ocurre respecto de la proximidad a las ciudades favoreciendo la oportunidad de invertir y el éxito en el emprendimiento (Dijkstra et al., 2015; Cejudo et al., 2020a). Este hecho afecta al trabajo femenino de forma clara ya que, partiendo de unos niveles globales de empleo inferiores al de su peso demográfico, su presencia se reduce aún más en los entonos lejanos y profundos. Estas situaciones se agudizan si, además, es ella la emprendedora frente a los casos en los que es solo trabajadora. Los jóvenes cuentan globalmente con niveles de representatividad laboral similar a la demográfica, si bien presentan mayores diferencias positivas al empleo en las tipologías territoriales extremas: en los entornos más dinámicos liderados por la mujer y en los más profundos por el hombre.

La ejecución del Eje LEADER ha estado marcada por la crisis económica y financiera desencadenada en 2008, afectando a todo el periodo de su implementación. Tanto las dificultades, cuando no imposibilidad, de encontrar trabajo en sectores fuertemente demandantes de mano de obra como la construcción, la hostelería o la restauración durante la "gran recesión" (Martín et al., 2020) como la normalización de un mercado laboral más flexible, "flexiseguridad", conducen al asalariado, en unos casos, y al que se enfrenta por primera vez a la consecución de un empleo, en otros, a convertirse en "empresario por necesidad" (Álvarez-Sousa, 2019; Martín \& Tovar, 2019;). Este contexto, para el conjunto de Andalucía, se penaliza, respecto del periodo 2000-2006, fuertemente la inversión, apenas 
supera el $55 \%$ de aquella, y escasamente el empleo, que alcanza el $84 \%$ de los 24521 del periodo anterior (Cejudo et al., 2017). Además, la ratio entre el empleo mantenimiento y creado también se incrementa en favor del primero ya que durante la etapa de bonanza sólo el 52,8 \% fue empleo consolidado mientras que durante la de crisis esto ocurría en casi 8 de cada 10 casos. Por tanto, la crisis en relación con LEADER se traduce, en términos cuantitativos, en una drástica reducción de la inversión media por proyecto que pretende consolidar el trabajo existente ya que el nuevo apenas supone algo más del 40 \% del periodo de programación anterior cuando se alcanzaron los 11598 nuevos empleos. Los datos del empleo joven no son comparables metodológicamente al no tener datos del trabajo mantenido, pero sí lo son los de la mujer. Sus valores llegaron a los 8913 empleos frente a los 9956 del periodo 2000-2006, lo que supone en términos relativos 5 puntos menos, 47,3 y 42,9\% respectivamente, en relación con el empleo total; comportamiento muy positivo si tenemos en cuenta lo comentado hasta ahora. Finalmente, si solo tenemos en cuenta el empleo creado, y asumiendo que, como ya se dijo, es muy inferior al del periodo anterior, 4888 frente a 11598, el ocupado por las mujeres en 2007-2013 supone el 49,6 \% y el de los jóvenes el 49,9\% de este. Las cifras de 20002006 fueron el 47,9 y el 41,2\%, respectivamente, valor este último muy condicionado con el cambio metodológico que considera joven a los menores de 30 años mientras que se eleva a 35 en 2007-2013. Estas cifras relativas nos muestran el alcance de la participación de la mujer en el empleo, no así de los jóvenes por las razones comentadas.

Ahora bien, el comportamiento de los promotores es muy desigual y varía según territorios, en parte, debido a la mayor o menor representación de cada uno de ellos en los órganos de decisión de los diferentes GAL, encargados de establecer las orientaciones y los objetivos de las correspondientes Estrategias de Desarrollo Local. No en vano, éstas sufrieron varias modificaciones, en sintonía con los cambios habidos a escala europea, nacional y regional que ponían el foco en objetivos horizontales como el cambio climático, que supusieron la eliminación de propuestas y proyectos particulares adaptados a las problemáticas y potencialidades de los territorios (Navarro et al., 2021). Como ya se señaló, LEADER sigue siendo controlado por las élites políticas y económicas locales así como por instituciones externas (Furmankiewicz \& Macken-Walsh, 2016).

Son, globalmente, las Sociedades Mercantiles las que más empleo generan, mayoritariamente, consolidando el existente, sobre todo si hablamos de las Sociedades Anónimas en el que solo 1 de cada 10 es nuevo, y, además, localizan sus actuaciones en los territorios intermedios y urbanos, fundamentalmente. Las Limitadas son las que más empleo generan y tienen una muy 
relevante presencia en el mundo rural donde aportan casi la mitad del empleo total así como del empleo creado. El menor capital social requerido, 3000€, para su constitución, unos trámites administrativos más flexibles y su carácter más familiar y de pocos socios, entre otros aspectos, las convierten en idóneas para emprender y autoemplearse colectivamente asumiendo un menor riesgo en tiempos de crisis, especialmente en el mundo rural. Mención aparte merecen las Cooperativas que, como fórmula de economía social, recurren a estas ayudas para mantener, fundamentalmente, el empleo de sus socios a través, en la mayoría de los casos, de su modernización tecnológica. Se favorece con ello los procesos de activación y consolidación del capital social esenciales en las dinámicas de desarrollo rural (Esparcia \& Abassi, 2020), evidenciando, además, la significación que el sector agroindustrial ha adquirido en LEADER durante 2007-2015 en Andalucía (Belliggiano et al., 2020). Su presencia ha sido más evidente en espacios interiores y montanos, como pueden ser la Penibética y la Subbética, ligados al olivar (Pérez-González \& Valiente-Palmay, 2021).

El papel de los actores públicos, sean las Corporaciones Locales o los GAL, en términos de empleo ha sido muy limitado por la imposibilidad legal de invertir en proyectos productivos. A lo que se añade las limitaciones financieras y los escasos presupuestos de las haciendas locales lastradas por la austeridad impuesta desde Bruselas tras nuestro rescate financiero. Ahora bien, la constatación estadística anterior no nos debería hacer olvidar que las actuaciones de las Corporaciones Locales tienen una enorme incidencia en la calidad de vida de los habitantes de sus municipios. Ello es así tanto por el conocimiento profundo e integral de los problemas de su comunidad como por ser los más implicados en los espacios donde lo privado no llega, lo que las convierte en actores propiciadores de desarrollo e innovación, especialmente en los municipios medianos y pequeños (OCDE, 2006; Neumeier, 2016), aunque quede aún mucho por mejorar a este respecto. En el caso de los GAL son conocidos los procesos de burocratización y escasa participación ciudadana, especialmente de mujeres y de jóvenes, en los que se encuentran aún inmersos (Viladomiu et al., 2010; Augustyn \& Nemes, 2014); las injerencias que se producen desde las instancias regionales (Navarro et al., 2015) limitando tanto el principio básico de subsidiariedad (Tirado \& Hernández, 2019) como su labor dinamizadora (Sacristán et al., 2016), etc. Ahora bien, todo ello no nos debe hacer olvidar ni su irrelevancia en relación con la generación de empleo ni que cuando lo hace éste se localiza en los entornos intermedios, penalizando a los territorios más vulnerables y rurales.

En este sentido, durante el periodo de programación 2007-2013 se asistió a una acusada pérdida de capacidad en la toma de decisiones por parte de los Grupos de Acción Local. 
Requerimientos, dilatación temporal de los procedimientos, rígidas exigencias y escasa flexibilidad para adaptarse a las específicas circunstancias de cada proyecto y promotor, menor independencia a la hora de decidir hacia qué y en qué cuantía dirigir el presupuesto, restaron al enfoque gran parte de sus especificidades: innovación, gobernanza, participación en la toma de decisiones, enfoque territorial, etc. Ello pudo influir en la menor atención a determinados colectivos, como eran mujeres y jóvenes, mermando su incidencia socioterritorial. La situación de crisis, que obligó a reducir, a mitad de periodo, al mínimo exigido los fondos dirigidos a LEADER por falta de propuestas, y los mayores controles derivados de la normativa FEADER hizo de este la función principal del personal de los Grupos de Acción Local. Lo que no cambió es que la apuesta y atención hacia el enfoque LEADER por parte de las administraciones nacionales y regionales siguió siendo más un compromiso que un verdadero apoyo y respaldo a su filosofía.

La relevancia de las Personas Físicas en relación con el empleo tiene que ver más con aspectos "cualitativos" que cuantitativos; más con los territorios, el perfil de los beneficiarios afectados y con el hecho de que emprendedor y trabajador básicamente coinciden, que con el volumen en sí del empleo generado.

En primer lugar, lo relevante de este actor es su apuesta por el mundo rural que alcanza valores máximos en los espacios más alejados, como es el profundo, sobre todo si tenemos en cuenta que son estos espacios, los más vulnerables y de menor dinamismo, los que se ven menos favorecidos por las actuaciones LEADER. Son aquellos espacios en los que su población no solo es, sino que se siente, más pobre, lo que requiere la implementación de políticas territoriales que consideren esta heterogeneidad en su diseño a escala nacional (García-Carro \& SánchezSellero, 2019) contemplando a estos espacios como territorios-recurso y no solo como territoriosproblema, tal y como hasta ahora han venido siendo considerados (Molina, 2021).

En segundo lugar, en casi la mitad de los casos dicho empleo es nuevo. Emergen nuevos emprendedores ligados a actividades de servicios profesionales y turismo rural (Alario \& Morales, 2016) así como una generación de jóvenes, muy formados, que ha vuelto a ver el medio rural -con buenas infraestructuras de comunicación y de conexión de red-como un lugar de producción e innovación (Shucksmith, 2010; Savall et al., 2019; Copus, 2020), siendo más ellas que ellos las protagonistas (Baylina, 2019; Pallarès-Barbera \& Casellas, 2019) en los entornos próximos y al contrario en los alejados. 
Finalmente, estas luces que se vislumbran en el desarrollo del mundo rural, y que parecen haberse reforzado como consecuencia de la COVID19, no deben hacernos olvidar que los jóvenes y las mujeres son los colectivos que más dificultades siguen encontrando a la hora de emprender dentro de LEADER (Cejudo et al., 2020b); que persiste aún la división de los roles de género, incluso cuando es solo la mujer la que trabaja dentro de la unidad familiar (Baylina et al., 2019; García-Román, 2020), y que en la sociedad española la precarización del empleo y del salario ha dejado de ser excepción para convertirse en norma para gran parte de la población, fundamentalmente, si es joven y mujer (Muñoz \& Santos, 2018).

Agradecimientos: Investigación financiada por el Ministerio de Economía, Industria y Competitividad. Proyecto de Investigación "Éxitos y fracasos en la práctica del desarrollo rural neo-endógeno en la Unión Europea (1991-2013), RURALWIN". CSO2017-89657-P.

Declaración responsable: Las/os autoras/es declaran que no existe ningún conflicto de interés con relación a la publicación de este artículo. Las tareas se han distribuido de la siguiente manera: el artículo ha sido coordinado por Eugenio Cejudo. Las/os cuatro autoras/es han participado en la revisión bibliográfica y en la redacción del mismo. La elaboración de las bases de datos y su posterior tabulación fue realizada por E. Cejudo y F. Navarro mientras que de las salidas cartográficas se encargaron J.A. Cañete y N. Ruiz. El análisis estadístico y cartográfico de los resultados obtenidos se llevó a cabo por los cuatro autores del trabajo. 


\section{Bibliografía}

Alario, M., \& Morales, E. (2016). Iniciativas de las mujeres: Emprendimiento y oportunidades en el espacio rural de Castilla y León. Documents d'Anàlisi Geogràfica, 62, 613637, https://doi.org/10.5565/rev/dag.369

Alario, M., \& Morales, E. (2020). Sostenibilidad y políticas de desarrollo rural. Cuadernos Geográficos, 59(1), 224-246. http://dx.doi.org/10.30827/cuadgeo.v59i1.8642

Álvarez-Sousa, A. (2019). Emprendedores por necesidad. Factores determinantes. Revista Española de Investigaciones Sociológicas, 166, 3-24. http://dx.doi.org/10.5477/cis/reis. 166.3

Augustyn, A.M., \& Nemes, G. (2014). Catching up with the West? Europeanisation of Rural Policies in Hungary and Poland. Studies in Agricultural Economics, 116, 114121. http://dx.doi:10.7896/j.1419

Baraja, E., Herrero, D., Martínez, M., \& Plaza, J.I. (2019). Turismo y desarrollo vitivinícola en espacios de montaña con "alta densidad patrimonial." Cuadernos de Turismo, 43, 97122. http://dx.doi:10.6018/turismo.43.04

Baylina, M. (2019) La mujer como eje vertebrador de la nueva ruralidad. Un estado de la cuestión. In E. Cejudo \& F. Navarro (Eds), Despoblación y Transformaciones Sociodemográficas de los Territorios Rurales: Los Casos de España, Italia y Francia (pp. 153-176). Universidad de Salento.

Baylina, M., Villarino, M., García, M.D., Mosteiro, M.J., Porto, A.M., \& Salamaña, I. (2019). Género e innovación en los nuevos procesos de re-ruralización en España. Finisterra - Revista Portuguesa de Geografia, 54, 75-91. http://dx.doi:10.18055/Finis16053

Belliggiano, A., Cejudo, E., \& De Rubertis, S. (2020). The Role of Agriculture in Rural Development in Spain and Italy within the Framework of the LEADER 2007-2013 Programming Period. In E. Cejudo \& F. Navarro (Eds), Neoendogenous Development in European Rural Areas. Results and lesson (pp. 149-180). Springer.

Bosworth, G. Rizzo, F., Marquardt, D., Strijker, D., Haartsen, T., \& Thuesen, A.A. (2016). Identifying social innovations in European local rural Development initiatives. Innovation: The European Journal of Social Science Research, 29, 442461. http://dx.doi:10.1080/13511610.2016.1176555 
Bosworth, G., Price, L., Hakulinen, V., \& Marango, S. (2020). Rural Social Innovation and Neoendogenous Rural Development. In E. Cejudo \& F. Navarro (Eds.), Neoendogenous Development in European Rural Areas. Results and Lessons (pp. 21-32). Springer.

Brezzi, M., Dijkstra, L., \& Ruiz, V. (2011). OECD Extended Regional Typology: The Economic Performance of Remote Rural Regions (OECD Regional Development Working Papers 6 No. 2011/06). OECD Publishing. https://doi.org/10.1787/20737009

Camarero, L. (2019). Los patrimonios de la despoblación: la diversidad del vacío. Revista PH, 98, 50-69. www.iaph.es/revistaph/index.php/revistaph/article/view/4517

Canales, G., \& López, A. (2013). La palmera en el paisaje de huerta del Bajo Segura. Un elemento identitario necesitado de protección. E-rph: Revista electrónica de Patrimonio Histórico, 13, 4-39. https://doi.org/10.30827/e-rph.v0i13.3488

Cañete, J., Navarro, F., \& Cejudo, E. (2018). Territorially unequal rural development: The cases of the LEADER Initiative and the PRODER Programme in Andalusia (Spain). European Planning Studies, 26, 1-19. http://dx.doi:10.1080/09654313.2018.1424118

Cañete, J., Nieto, A., Cejudo, E. \& Cárdenas, G. (2020). Territorial Distribution of Projects within the LEADER Approach (2007-2013) in Extremadura and Andalusia. In: Cejudo, E. and Navarro, F. (Eds.) Neoendogenous Development in European Rural Areas. Results and Lessons (pp. 87109). Cham, Switzerland: Springer. ISBN 978-3-030-33462-8.

Cañizares, M.C. (2020). Procesos y retos en torno al patrimonio y a los paisajes culturales: una reflexión teórica desde la geografía española. Revista de Geografía Norte Grande, 76, 189212. http://dx.doi.org/10.4067/S0718-34022020000200189

Cañizares, M.C., \& Ruiz, A.R. (2020). Paisajes del viñedo, turismo y sostenibilidad: interrelaciones teóricas y aplicadas. Investigaciones Geográficas, 74, 928. https://doi.org/10.14198/INGEO2020.CRRP

Cárdenas, G, \& Nieto, A. (2017). Towards Rural Sustainable Development? Contributions of the EAFRD 2007-2013 in Low Demographic Density Territories: The Case of Extremadura (SW Spain). Sustainability, 9(7), 1173. https://doi.org/10.3390/su9071173

Cejudo, E., Navarro, F., \& Cañete, J.A. (2016a). Evolución y distribución territorial de los trabajadores eventuales agrarios subsidiados en Andalucía. Boletín de la Asociación de Geógrafos Españoles, (72), 117-147. https://doi.org/10.21138/bage.2334 
Cejudo, E., Navarro, F.A., \& Maroto, J.C. (2016b). Perceptores del subsidio y de la renta agraria en el sur de España: Evolución, diferencias territoriales y estructura por edad y sexo. AGER, 20, 32-72. http://ruralager.org/wp-content/uploads/Ager-20-02-Cejudo-NavarroMaroto.pdf

Cejudo, E., Navarro, F.A., \& Camacho, J.A. (2017). Perfil y características de los beneficiarios finales de los Programas de Desarrollo Rural en Andalucía. LEADER+ y PRODER2 (2000-2006). Cuadernos Geográficos, 56, 155-175. https://doi.org/10.30827/cuadgeo.v56i2.5237

Cejudo, E., Cañete, J.A., Navarro, F., \& Ruiz, N. (2020a). Entrepreneurs and Territorial Diversity: Success and Failure in Andalusia 2007-2015. Land, (8), 262. https://doi.org/10.3390/land9080262

Cejudo, E., Navarro, F., \& Cañete, J.A. (2020b). Young and women entrepreneurs in neoendogenous development. In E. Cejudo \& F. Navarro (Eds.), Neoendogenous Development in European Rural Areas. Results and Lessons (pp. 209-234). Springer.

Cherayi, S., \& Jose, J.P. (2016). Empowerment and social inclusion of Muslim women: Towards a new conceptual model. Journal of Rural Studies, 45, 243251. http://doi.org/10.1016/j.jrurstud.2016.04.003

Copus, A. (2020) European Shrinking Rural Areas: Challenges, Actions and Perspectives for Territorial Governance (ESCAPE). Interim Report. ESPON. https://www.espon.eu/escape

Dargan, L., \& Shucksmith, M. (2008). LEADER and Innovation. Sociologia Ruralis, 48, 274291, http://doi.org/10.1111/j.1467-9523.2008.00463.x

Dax T., Strahl W., Kirwan J., \& Maye D. (2016). The Leader programme 2007-2013: Enabling or disabling social innovation and neo-endogenous development? Insights from Austria and Ireland. European Urban and Regional Studies, 23, 5668. https://doi.org/10.1177/0969776413490425

De Cos, O., \& Reques, P. (2019). Vulnerabilidad territorial y demográfica en España. Posibilidades del análisis multicriterio y la lógica difusa para la definición de patrones espaciales. Journal of Regional Research Investigaciones Regionales, 45, 201225. https://investigacionesregionales.org/wp-content/uploads/sites/3/2019/12/11.Decos.pdf 
Delin, M. (2012). The role of farmers in Local Action Groups: The case of the national network of the Local Action Groups in the Czech Republic. Agricultural Economics - Czech, 58, 433442. http://doi.org/10.17221/148/2011-AGRICECON

Dijkstra, L., Garcilazo, E., \& McCann, P. (2015). The effects of the global financial crisis on European regions and cities. Journal of Economic Geography, 15, 935 949. https://doi.org/10.1093/jeg/lbv032

Esparcia, J. (2014). Innovation and networks in rural areas. An analysis from European innovative projects. Journal of Rural Studies, 34, 1-14. https://doi.org/10.1016/j.jrurstud.2013.12.004

Esparcia J., Escribano J., \& Serrano J. (2015a). From development to power relations and territorial governance: Increasing the leadership role of LEADER Local Action Groups in Spain. Journal of Rural Studies, 42, 29-42. https://doi.org/10.1016/j.jrurstud.2015.09.005

Esparcia, J., Escribano, J., \& Buciega, A. (2015b). A perspective of LEADER method in Spain based on the analysis of Local Action Groups. In L. Gramberg, K. Andersson \& I. Kovách (Eds.), Evaluating the LEADER Approach to Rural Development. Grass-Roots Experiences of the LEADER Programme (pp. 33-51). Ashgate.

Esparcia, J.. \& Abassi, F. (2020). Territorial Governance and Rural Development: Challenge or Reality? In E. Cejudo \& F. Navarro (Eds.), Neoendogenous Development in European Rural Areas. Results and Lessons (pp. 33-60). Springer.

Esteve, E. (2018). Evolución moderna de la dinámica demográfica en el territorio andaluz. In J. A. Márquez \& R. Jordá (Eds.), Ciencia Regional y Andalucía a partir de la visión del geógrafo Gabriel Marco Cano García. Un homenaje a su vida y obra (pp. 499-518). Editorial Universidad de Sevilla.

European Commission (2006). Directorate-General for Agriculture and Rural Development. The Leader approach: A basic guide. Publications Office.

European Commission (2017). Ex post evaluation of rural development programmes 2007-2013. Information Report. European Sconomic and Social Committee. $\quad$ https://www.eesc.europa.eu/en/our-work/opinions-informationreports/information-reports/ex-post-evaluations-rural-development-programmes-20072013

Fernández, J., \& Vidal, M.J. (2020). Wine routes as engines of socio-territorial dynamisation: the case of Castilla y León. Boletín de la Asociación de Geógrafos Españoles, (84). https://doi.org/10.21138/bage.2789 
Furmankiewicz, M., \& Macken-Walsh, A. (2016). Government within governance? Polish rural development partnerships through the lens of functional representation. Journal of Rural Studies, 46, 12-22. https://doi.org/10.1016/j.jrurstud.2016.05.004

García-Carro, B., \& Sánchez-Sellero, M.C. (2019). Medición de la pobreza subjetiva en España y su localización espacial. Revista Española de Investigaciones Sociológicas, 165, 83100. http://doi.ogr/10.5477/cis/reis. 165.83

García-Román, J. (2020). La división de los roles de género en las parejas en las que solo trabaja la mujer en Estados Unidos y España. Revista Española de Investigaciones Sociológicas, 170, 73 94. http://doi.org/10.5477/cis/reis. 170.73

High, C., \& Nemes, G. (2007). Social Learning in LEADER: Exogenous, Endogenous and Hybrid Evaluation in Rural Development. Sociologia Ruralis, 47, 103119. http://doi.org/10.1111/j.1467-9523.2007.00430.x

Labianca, M., De Rubertis, S., Belliggiano, A., \& Salento, A. (2016). Innovation in rural development in Puglia, Italy: Critical issues and potentialities starting from empirical evidence. Studies in Agricultural Economics, 118, 1-9. http://doi.org/10.22004/ag.econ.234968

Lacquement, G. (2016). Penser l'innovation dans les régions rurales défavorisées d'Allemagne orientale. Bulletin de l'association de géographes français. Géographies, 93, 145 164. http://doi.org/10.4000/bagf.849

Larrubia Vargas, R., Navarro Rodríguez, S.R., \& Natera Rivas, J.J. (2019). Sobre los factores de diferenciación de la diversidad rural y las opciones de su clasificación: ensayo metodológico en la provincia de Málaga. Boletín de la Asociación de Geógrafos Españoles, (81). https://doi.org/10.21138/bage.2697

Lasarte López, J., Rodero Cosano, M.L., \& Salinas Pérez, J.A. (2016). La medición de la ruralidad y sus dimensiones en Andalucía a través de modelos de indicadores sociales. In Treinta años de integración en Europa desde la perspectiva regional: balance y nuevos retos. Comunicación presentada en la XLII Reunión de Estudios Regionales (AECR). https://old.reunionesdeestudiosregionales.org/Santiago2016/htdocs/pdf/p1902.pdf Lukić, A., \& Obad, O. (2016). New Actors in Rural Development-The LEADER Approach and Projectification in Rural Croatia. Sociologija i Prostor, 54, 71 90. http://doi.ogr.10.5673/sip.54.1.4 
Larrubia, R., \& Natera, J.J. (2019). Envejecimiento y masculinización de la población rural andaluza. In E. Cejudo \& F.A. Navarro (Eds.), Despoblación y transformaciones sociodemográficas de los territorios rurales: Los casos de España, Italia y Francia (pp. 121-152). Universidad de Salento.

Leibundgut, C., \& Kohn, I. (2014). European traditional irrigation in transition part II: traditional irrigation in our time-decline, rediscovery and restoration perspectives. Irrigation and Drainage, 63(3), 294-314. http://doi.org/10.1002/ird.1825

Maroto-Martos, J.C., \& Pinos-Navarrete, A. (2019). ¿EEl turismo rural freno de la despoblación? El caso del sur de España. In E. Cejudo \& F.A. Navarro (Eds.), Despoblación y transformaciones sociodemográficas de los territorios rurales: los casos de España, Italia y Francia (pp. 327-374). Universidad de Salento.

Martín, M., Castro, C. de, \& Calderón, D. (2020). Welfare Citizenship in the Shadow of the Recession in Spain: The Case of Households in Hardship. REIS, 169, 85102, http://doi.org/10.5477/cis/reis. 169.85

Martín, P., \& Tovar, F.J. (2019). Desmontando la seguridad en las políticas de empleo: La propuesta europea de flexiguridad. Revista Internacional de Sociología, 77, e124. http://doi.org/10.3989/ris.2019.77.2.17.139

Mata, R. (2014). Paisajes para un desarrollo sustentable y participativo. Revista Urbano, 30, 821. http://revistas.ubiobio.cl/index.php/RU/article/view/206/185

Mayordomo, S. \& Hermosilla, J. (2019). Evaluación del patrimonio cultural: la Huerta de Valencia como recurso territorial. Boletín de la Asociación de Geógrafos Españoles, (82). http://dx.doi.org/10.21138/bage.2790

Molina, M. (2021). Hacia una nueva frontera rural-urbana. In El papel de la agricultura y la ganadería sostenibles en la lucha contra el despoblamiento. Agricultura y ganadería familiar en España. Anuariao 2021 (pp. 34-39). Fundación de Estudios Rurales. https://www.upa.es/upa/publicaciones-upa/2021/3926/

Molinero, F. (2019). El espacio rural de España: Evolución, delimitación y clasificación. Cuadernos Geográficos, 58, 19-56. http://doi.org/10.30827/cuadgeo.v58i3.8643

Molinero, F., \& Tort, J. (2018). Paisajes Patrimoniales de España. Ministerio de Agricultura, Pesca y Alimentación, Ministerio para la Transición Ecológica-UAM ediciones. 
Molinero, F., \& Alario, M. (2019). Ante el reto de la despoblación de la España interior y sus diferencias regionales. In E. Cejudo \& F. Navarro (Eds.), Despoblación y Transformaciones Sociodemográficas de los Territorios Rurales: Los Casos de España, Italia y Francia (pp. 41-70). Universidad de Salento.

Moulaert, F., Mehmood, A., MacCallum, D., \& Leubolt, B. (2017). Social innovation a Trigger for Transformations. https://op.europa.eu/en/publication-detail/-/publication/a7b4de0a-107011e8-9253-01aa75ed71a1/language-en

Muñoz, D., \& Santos, A. (2018). En las cárceles del capital humano. Nuevas precariedades y subjetivación de los procesos contemporáneos de precarización. Zambra/Baladre.

Nardone, G., Sisto, R., \& Lopolito, A. (2010). Social Capital in the LEADER Initiative: A methodological approach. Journal of Rural Studies, 26, 6372. http://doi.org/10.1016/j.jrurstud.2009.09.001

Navarro, F., Woods, M., \& Cejudo, E. (2015). The LEADER Initiative has been a Victim of Its Own Success. The Decline of the Bottom-Up Approach in Rural Development Programmes. The Cases of Wales and Andalusia. Sociologia Ruralis, 56, 270288. http://doi.org/10.1111/soru. 12079

Navarro, F., Cejudo, E., \& Cañete, J.A. (2021). The Lack of Attention Given by Neoendogenous Rural Development Practice to Areas Highly Affected by Depopulation. The Case of Andalusia (Spain) in 2015-2020 Period. European Countryside, 13(2), 352367. http://doi.org/10.2478/euco-2021-0022

Neumeier, S. (2016). Social innovation in rural development: Identifying the key factors of success. The Geographical Journal, 183, 1-27. http://doi.org/10.1111/geoj.12180

Nogué, J. (2016). El reencuentro con el lugar: Nuevas ruralidades, nuevos paisajes y cambio de paradigma. Documents d'Anàlisi Geogràfica, 68, 502. http://do.org/10.5565/rev/dag.373

OECD (2006). The New Rural Paradigm: Policies and Governance. OECD Publishing.

Pallarès-Barbera, M., \& Casellas, A. (2019). Social networks as the backbone of women's work in the Catalan Pyrenees. Eur. Urban Reg. Stud, 26, 6579. http://doi.org/10.1177/0969776417730864 
Papadopoulou, E., Hasanagas, N., \& Harvey, D. (2011). Analysis of rural development policy networks in Greece: Is LEADER really different? Land Use Policy, 28(4), 663673. https://doi.org/10.1016/j.landusepol.2010.11.005

Pawlowska, A. (2017). Territorial partnerships in rural regions. Neo-institutional perspective. Polish Sociological Review, 197(1), 95-108. http://www.jstor.org/stable/26383069

Pérez-González, M.C., \& Valiente-Palma, L. (2021). Cooperative Societies and Sustainability: A Spatial Analysis of Andalusia as a Tool for Implementing Territorial Development Policies, Strategies and Initiatives. Sustainability, 13, 609. https://doi.org/10.3390/su13020609

Plaza, J.I., Herrero, D., Martínez, M., \& Baraja, E. (2019). Paisaje de huertas periurbanas y ciudad: algunos ejemplos de Castilla y León. Cuadernos Geográficos, 58(2), 168193. https://doi.org/10.30827/cuadgeo.v58i2.7431

Pollermann K., Raue P., \& Schnaut G. (2013). Rural Development experiences in Germany: opportunities and obstacles in fostering smart places through LEADER. Studies in Agricultural Economics, 115, 111-117. http://dx.doi.org/10.7896/j.1228

Reig, E., Goerlich, F.J., \& Cantarino, I. (2016). Delimitación de áreas rurales y urbanas a nivel local: demografía, coberturas del suelo y accesibilidad. Fundación BBVA.

Rodríguez M., Sánchez L.M., Cejudo E., \& Camacho J.A. (2019): Variety in local development strategies and employment: LEADER programme in Andalusia. Agricultural Economics - Czech, 65, 43-50. http://doi.org/10.17221/106/2018-AGRICECON

Sacristán, H., Martínez, F., \& Yagüe, J.L. (2016). Los órganos de decisión de los grupos de acción local en el periodo 2007-2013 en España: Relaciones entre los actores del medio rural. Revista Española de Estudios Agrosociales y Pesqueros, 245, 4766. https://www.miteco.gob.es/ministerio/pags/Biblioteca/Revistas/pdf_REEAP\%2FPdf_REEA P_r245_47_66.pdf

Salamaña, I., Baylina, M., García, M.D., Porto, A.M., \& Villarino, M. (2016). Dones, trajectòries de vida i noves ruralitats. Documents d'Anàlisi Geogràfica, 62, 661 681. http://doi.org/10.5565/rev/dag.403

Sánchez, L.M. (2018). Ciudades medias y desarrollo regional en Andalucía en el siglo XXI. In J.A. Márquez \& R. Jordá (Eds.), Ciencia regional y Andalucía a partir de la visión del geógrafo Gabriel Marco Cano García. Un homenaje a su vida y obra (pp. 179-192). Editorial Universidad de Sevilla. 
Sánchez-Zamora, P., Gallardo-Cobos, R., \& Ceña-Delgado, F. (2014). Rural areas face the economic crisis: Analyzing the determinants of successful territorial dynamics. Journal of Rural Studies, 35, 11-25.-http://doi.org/10.1016/j.jrurstud.2014.03.007

Savall, N.V., Pizarro, J.E., \& Valero, D.E. (2019). Models de vida femenins en el medi rural. Un cas d'estudi a la Sierra del Segura (Albacete). Documents d'Anàlisi Geogràfica, 65, 139161. http://doi.org/10.5565/rev/dag.449

Shucksmith, M. (2010). How to promote the role of youth in rural areas of Europe? Report for European Parliament. Directorate General for Internal Policies, Policy Department B: Structural and Cohesion Policies.

https://www. europarl.europa.eu/RegData/etudes/note/join/2010/438620/IPOL-

AGRI_NT(2010)438620_EN.pdf

Silva, R., \& Fernández, V. (2020). Unesco's territorial regarding (and disregarding) on its territorial heritage programmes: World Heritage Convention, Man and the Biosphere Programme (MaB) and International Geoscience and Geoparks Programme. Boletín de la Asociación de Geógrafos Españoles, (86). https://doi.org/10.21138/bage.2987

Steiner, A., Caló, F., \& Shucksmith, M. (In press). Rurality and social innovation processes and outcomes: A realist evaluation of rural social enterprise activities. Journal of Rural Studies. https://doi.org/10.1016/j.jrurstud.2021.04.006

Teilmann, K. (2012). Measuring social capital accumulation in rural development. Journal of Rural Studies, 28, 458-465. http://doi.org/10.1016/j.jrurstud.2012.10.002

Thuesen, A.A. (2010). Is LEADER elitist or inclusive? Composition of Danish LAG boards in the 2007-2013 rural development and fisheries programmes. Sociologia Ruralis, 50, 31 45. https://doi.org/10.1111/j.1467-9523.2009.00500.x

Tirado, J.G., \& Hernández, M. (2019). Promoting tourism through the EU LEADER programme: Understanding Local Action Group governance. European Planning Studies, 27, 396414, http://doi.org/10.1080/09654313.2018.1547368

Vercher, N., Escribano J., \& Valero D.E. (2019). Models de vida femenins en el medi rural. Un cas d'estudi a la Sierra del Segura (Albacete). Documents d'Anàlisi Geogràfica, 65(1), 139161. https://doi.org/10.5565/rev/dag.449 
Viladomiu, L., Rosell, J., \& Francès, G. (2010). Factores determinantes de la participacion de la mujer como promotoras de proyectos Leader+. Revista Española de Estudios Agrosociales y Pesqueros, 226, 1-30.

https://www. mapa.gob.es/app/publicaciones/art_datos.asp?articuloid=1291\&codrevista=REE $\underline{A P}$ 